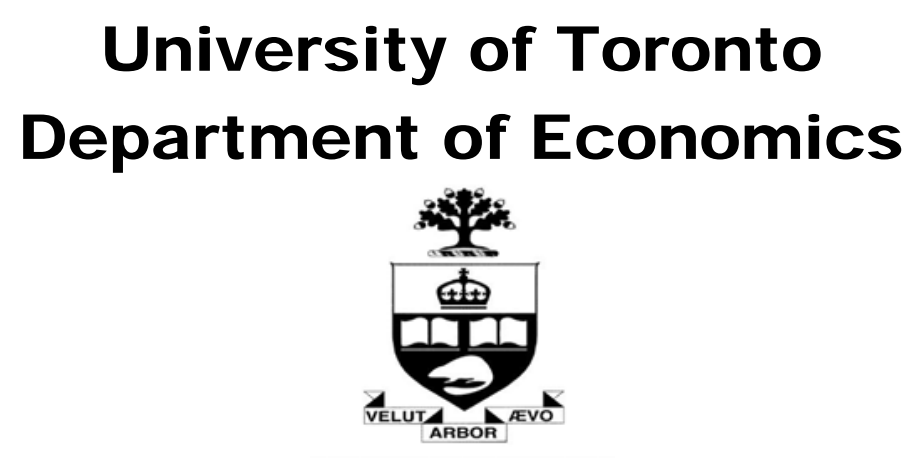

Working Paper 671

Structural Change and Aggregate Employment Fluctuations in China

By Wen Yao and Xiaodong Zhu

July 14,2020 


\title{
Structural Change and Aggregate Employment Fluctuations in China
}

\author{
Wen Yao \\ Tsinghua University
}

\author{
Xiaodong Zhu \\ University of Toronto
}

First Complete Draft: December 2017. This Version: July 2020.

\begin{abstract}
In developed countries, aggregate employment is strongly pro-cyclical and almost as volatile as output. In China, the correlation of aggregate employment and output is close to zero, and the volatility of aggregate employment is very low. We argue that the key to understanding the aggregate employment fluctuations in China is the labour reallocation between the agricultural and non-agricultural sectors, and that income effect plays an important role in determining the labour reallocation dynamics in both the long-run and short-run.
\end{abstract}

JEL Classification: E24, E32, O41

Keywords: Structural Change, Income Effect, Labour Reallocation, Employment Fluctuations, China

Yao, School of Economics and Management, Tsinghua University, email: yaow @ sem.tsinghua.edu.cn. Zhu, Department of Economics, University of Toronto, and PBC School of Finance, Tsinghua University, email: xiaodong.zhu@utoronto.ca. We would like to thank the editor, two annonymous referees, and participants at the 2016 PBC-SAIF Conference on Monetary Policy, 2016 Midwest Macro Meetings, 2017 Growth and Institution Program Meeting at Tsinghua University, 2017 and 2018 China Meeting of the Econometric Society, 2018 Annual Meeting of Society of Economic Dynamics, 2019 Bank of Canada-Tsinghua PBCSF-University of Toronto Conference on the Chinese Economy, and seminars at several universities and Federal Reserve Banks for their useful comments. Wen Yao acknowledges the financial support of the National Natural Science Foundation of China (Grant No. 71603144). 


\section{Introduction}

One salient feature of business cycles in developed countries is that aggregate employment has a strong positive correlation with aggregate output (pro-cyclical) and is almost as volatile as output. This is not the case in China. The correlation of the cyclical components of aggregate employment and output is close to zero, and the volatility of aggregate employment is also very low. These puzzling facts about aggregate employment fluctuations in China are present even after we carefully correct for some well-known measurement problems in the official employment and GDP series, and they are robust to different detrending methods. In this paper, we argue that the key to understanding the aggregate employment fluctuations in China is the labour reallocation between the agricultural and non-agricultural sectors, and that income effect plays an important role in determining the labour reallocation dynamics in both the long-run and short-run. Our argument is motivated by the following three sets of empirical facts.

First, at sector level, the cyclical properties of employments in China are similar to those in developed countries. For both China and the OECD countries, the volatility of sector employment relative to the volatility of sector GDP is high and employment is strongly pro-cyclical in the non-agricultural sector. In the agricultural sector, the relative volatility of employment is actually higher in China than in the OECD countries, and employment is acyclical in all the countries.

Second, we show that the differences in the aggregate moments between China and the developed countries are affected by the difference in the stage of structural change. Using a panel data of 40 countries from the Groningen Growth and Development Center (GGDC), we find that the comovement of aggregate employment and output at any point of time is negatively related to the current share of employment in agriculture at that time. Da-Rocha and Restuccia (2006) document that the average share of employment in agriculture has a negative effect on the correlation between aggregate employment and output. We find that even after controlling for the average share, the current share of employment in agriculture still matters. This dynamic effect of economic structure on aggregate employment fluctuations is particularly relevant for China, in which the share of employment in agriculture 
declined from 71 percent in 1978 to 27 percent in 2017. Therefore, any theory for explaining the aggregate employment fluctuations in China should be able to match the secular trend of labour reallocation out of agriculture.

Third and most important, for almost all the countries in GGDC dataset, we find that the ratio of the employment in agriculture to that in the non-agricultural sector is negatively correlated with per capita GDP over the business cycles. Boppart (2014) and Comin, Lashkari, and Mestieri (2020) emphasize that income effect is important in understanding the secular trend of labour reallocation from agriculture to manufacturing and services. Our new fact suggests that income effect is also important in determining labour reallocation between sectors at the business cycle frequency.

Given these facts, we construct a two-sector growth model with the non-homothetic CES preferences that is recently used by Comin, Lashkari, and Mestieri (2020). In this model, income effect plays an important role in labour allocation both in the long-run and at the business cycle frequency. Using expenditure and price data of 40 countries and a panel regression that is derived from our model, we first show empirically the presence of strong income effect. We then calibrate the parameters of our model so that it can account for the secular trend in labour reallocation from agriculture to non-agriculture in China. The calibration reveals that income effect is important in accounting for the long-run structural change in China. Without income effect, the model could not match the long-run structural change in China. Finally, we examine the calibrated model's implications for the labour market dynamics at the business cycle frequency. Fluctuations in this model are driven by productivity shocks in the two sectors. We find that our model can indeed account for the employment fluctuations at the sector level and in the aggregate for China. At the business cycle frequency, income effect is also important in matching business cycle moments in China. Without income effect, the model cannot generate the low correlation between aggregate employment and output, nor the negative correlation between relative employment in agriculture and aggregate income in China. Our model also does a good job in matching the structural change and aggregate employment fluctuations in a developed country like the US. In particular, our model implies a low employment-output correlation for China and, at the same 
time, a high employment-output correlation for the US.

The main contribution of our paper is documenting the importance of income effect in understanding aggregate employment fluctuations and constructing a model with income effect that can account for both the structural change in the long-run and employment fluctuations in the short run in China. As such, our paper is related to two strands of literature. First, it is related to the literature on structural change. See e.g., Caselli and Coleman (2001), Kongsamut, Rebelo, and Xie (2001), Ngai and Pissarides (2007), Acemoglu and Guerrieri (2008), and Herrendorf, Rogerson, and Valentinyi (2013). Most of the studies in this literature focus on understanding the sources of structural change in the long-run; our paper builds on this literature and studies the business cycle implications of income effect and show that it is important for understanding aggregate employment fluctuations in the short-run. Our paper is also related to the literature on business cycles in China. Brandt and Zhu (2000) is one of the first papers studying business cycles in China during the reform period. Their focus, however, is on understanding the relationship between GDP growth and inflation over the business cycles in the 1980s and early 1990s. Chang, Chen, Waggoner, and Zha (2016) is a more recent study of business cycles in China, and their focus is on understanding the weak correlation between investment and consumption in China since the late 1990s. Neither of these studies examines the relationship between aggregate employment and output. He, Chong, and Shi (2009) carry out an exercise of business cycle accounting for China in the spirit of Chari, Kehoe, and McGrattan (2007). They find that most of the fluctuations in aggregate employment can only be accounted for by variations in an unobserved labour wedge, highlighting the inability of a standard one-sector business cycle model in accounting for the employment fluctuations in China. Our paper shows that a standard two-sector model with non-homothetic CES preferences can account for the aggregate employment fluctuations in China without introducing a time-varying labour wedge.

There are two studies that are closely related to our paper. Da-Rocha and Restuccia (2006) is the first paper that documents the low correlation between aggregate employment and output in countries with a large agricultural sector. They use a two-sector real business cycle model to examine the role of labour realloca- 
tion in accounting for the cyclical behaviour of aggregate employment. To focus on cyclical fluctuations, they assume that each country is fluctuating around a steady state with a constant share of employment in agriculture. ${ }^{1}$ Since structural change - the secular decline of the agriculture's share of employment - is a very prominent phenomenon in China during the period we study, and since empirically the correlation between aggregate employment and output fluctuations is affected by the share of employment in agriculture at each point of time, not just the average of the share over a period of time, it is important to have a unified model that can account for both the secular trend of structural change and the employment fluctuations around the trend. We provide such a unified model in this paper.

Another closely related paper is the one by Storesletten, Zhao, and Zilibotti (2019), SZZ thereafter, who also use a two-sector model to account for both the structural change and aggregate employment fluctuations in China. We see four strengths of our paper. First, we show that income effect is empirically important at the business cycle frequency for a large panel of countries and quantitatively important for accounting for the aggregate employment fluctuations in China. In contrast, SZZ emphasize capital deepening within agriculture rather than income effect as the driving force for the labour reallocation between the two sectors. Note that although SZZ also consider income effect using a generalized Stone-Geary utility function, the income effect implied by the Stone-Geary utility function is very special and disappears in the long-run. As shown by Comin, Lashkari, and Mestieri (2020), a model with a more general form of income effect, i.e., preferences represented by a non-homothetic CES utility function, performs much better than the generalized Stone-Geary utility function in accounting for the secular trend of structural change across countries. In this paper, we use the more general non-homothetic CES utility function and show that it performs well in accounting for the labour reallocation over the business cycles and aggregate employment fluctuations in China. Second, all important endogenous variables in our paper, such as sector employment and output, have empirical counterparts that can be directly measured from available data. SZZ, however, assume that within agriculture there are two sub-sectors, tra-

\footnotetext{
${ }^{1}$ Moro (2012) uses a similar method to examine the impact of reallocation from manufacturing to services on the GDP volatility in US.
} 
ditional agriculture and modern agriculture, that cannot be directly observed nor identified in the data. Third, whereas SZZ assume an elasticity of substitution between the agricultural and non-agricultural goods that is greater than one, we find in our estimation that the elasticity of substitution between the agricultural and nonagricultural goods is less than one, which is consistent with the values used or estimated in the literature on structural change, e.g., Ngai and Pissarides (2007), Acemoglu and Guerrieri (2008), Herrendorf, Rogerson, and Valentinyi (2013), and Comin, Lashkari, and Mestieri (2020). An elasticity that is less than one implies that an exogenous increase in agricultural productivity would lead to a decline in the share of employment in agriculture. This is exactly what happened in China at the end of 1970s and early 1980s, when an institutional reform, the implementation of the household responsibility system, led to significant TFP growth (Lin, 1992) and faster labour productivity growth in agriculture. At the same time, the share of employment in agriculture declined (Brandt, Hsieh, and Zhu, 1998). Finally, our model does a much better job in matching the moments in the Chinese data. While SZZ's model can generate lower relative volatility of employment and lower employment-output correlation than a standard one-sector business cycle model, the values from their calibrated model are still significantly higher than those in the Chinese data.

\section{Data and Facts}

Before presenting our model, we first discuss the data and facts about the employment fluctuations in China and other countries. ${ }^{2}$

\subsection{Data}

For China, we use the official data published in the latest China Statistical Yearbook that can be accessed from the official website of the National Bureau of Statistics (http://data.stats.gov.cn/easyquery.htm?cn=C01). The annual data cover 40 years from 1978 to 2017 . For countries other than China, we use the annual sector-level

\footnotetext{
${ }^{2} \mathrm{~A}$ more detailed discussion of data is given in Appendix A.
} 
Figure 1: Employment Data in China
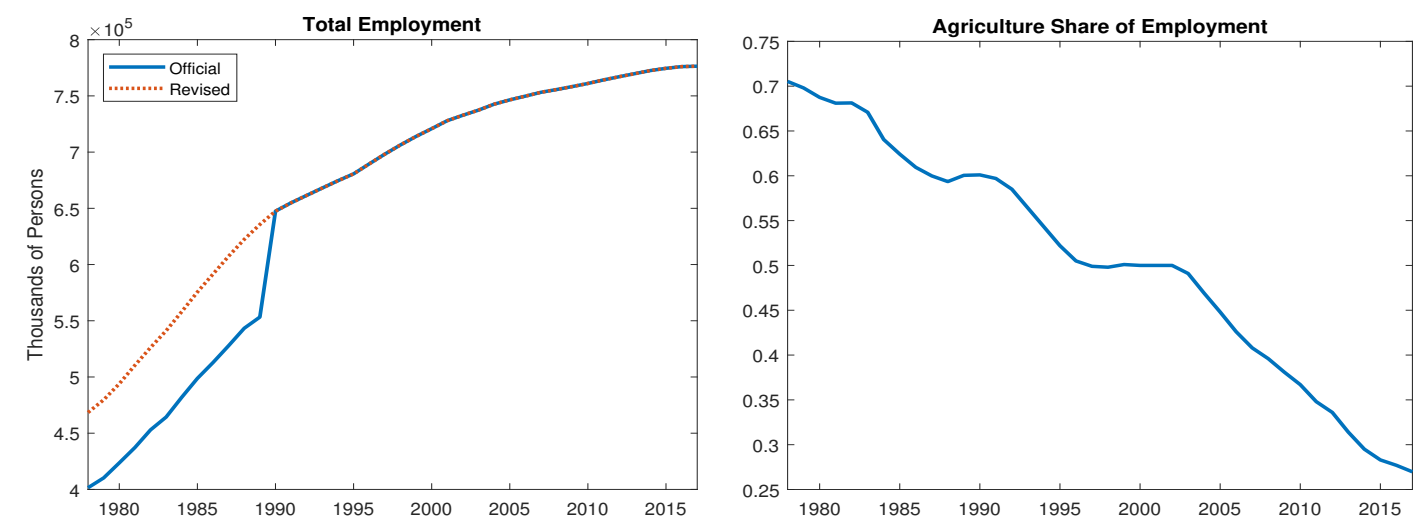

data on real GDP and employment from the GGDC's 10-Sector Database (Timmer, de Vries and de Vries (2015)), and aggregate the nine sectors outside agriculture into one non-agricultural sector. To be consistent with the sample size of the Chinese data, we use the latest 40 years available in the GGDC database. ${ }^{3}$

According to the official Chinese data, there is a discrete upward jump in total employment in 1990. Holz (2006) pointed out that this jump is due to a change in the official definition of employment after 1990 census, which broadened the coverage of the series. The published official data use the new definition for the years since 1990, but still use the old definition for the years prior to 1990 . We follow Brandt and Zhu (2010) and use the 1982 census data to adjust the employment data for the years before 1990 so that the entire employment series has a consistent coverage. The official and the revised total employment series are plotted in the left panel of Figure 1. We then apply the shares of employment in the agricultural and non-agricultural sectors from the official data to the revised total employment to generate employment series for the two sectors before 1990. Figure 1 also shows the agriculture's share of total employment in the right panel. ${ }^{4}$

\footnotetext{
${ }^{3}$ All OECD countries in the GGDC database have at least 40 years of data, but some developing countries in the database have less than 40 years of available data. For these countries, we use all the data available. Appendix A includes a list of countries we used and the sample period for each of the countries listed.

${ }^{4}$ Brandt and Zhu (2010) also pointed out some other problems in the official employment and GDP series. However, correction of these problems do not change the main facts we present in
} 
Given the revised employment data for China, we next present the facts on the cyclical properties of employment in China and compare them to those in developed countries. All the data used are first normalized by population and then detrended using hp-filter with a smoothing parameter of 100 .

\subsection{Facts}

We first document that China is different from developed countries in aggregate employment fluctuations, but similar to these countries in employment fluctuations at sector level. We then show that, across all countries, the correlation of aggregate employment and output is negatively related to the share of employment in agriculture. Finally, we show that the relative employment in agriculture is negatively correlated to the GDP per capita over the business cycles.

\subsubsection{Aggregate Employment Fluctuations}

Figure 2 plots cyclical movements of the aggregate employment and output for China and the US. Two observations are clear from the plots:

1. In China, the magnitude of fluctuations in the aggregate employment is much lower than that of the aggregate output. This is in stark contrast with the US, where the aggregate employment fluctuates almost as much as the aggregate output.

2. Aggregate employment is acyclical in China, while it is strongly pro-cyclical in the US.

this paper. In our main analysis here, we use the official series (with the correction for the total employment) because it is available for 40 years from 1978 to 2017, which are longer than the revised series from 1978 to 2010. Moreover, the official series are also used by other papers in the literature such as Storesletten, Zhao, and Zilibotti (2019). We report the revised series and related quantitative analysis in Appendix $\mathrm{H}$. 
Figure 2: Cyclical Fluctuations
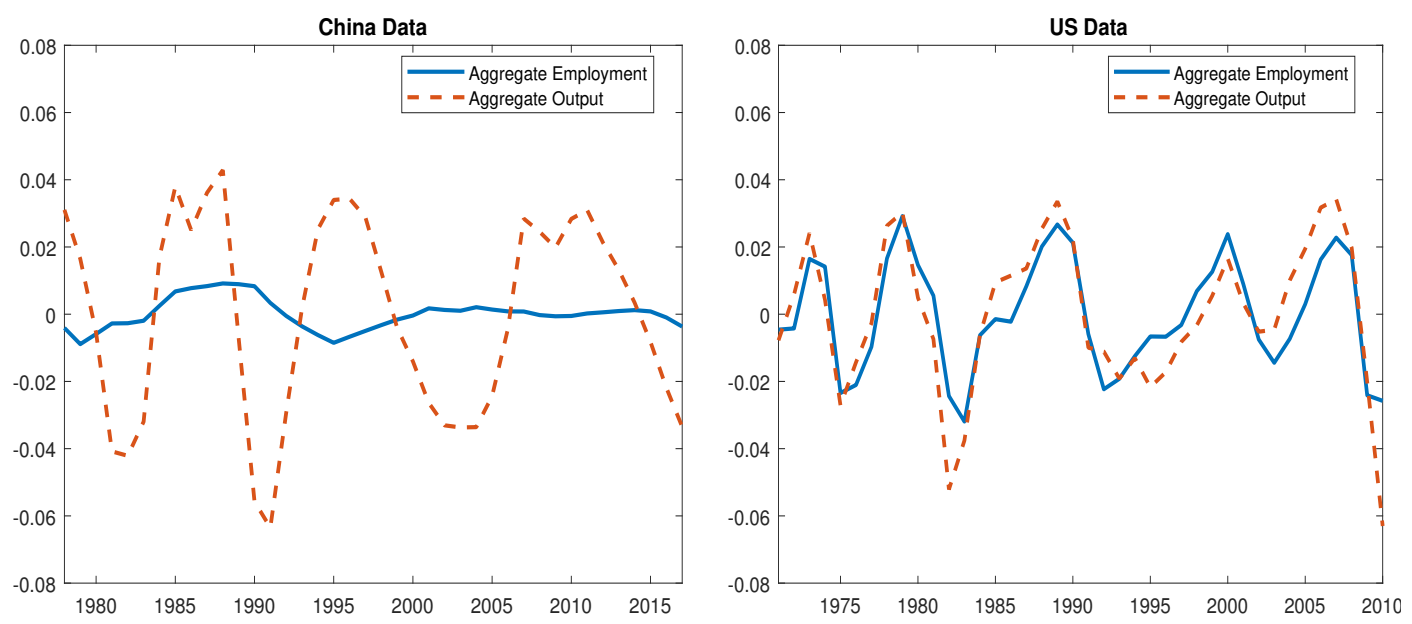

Table 1 presents the aggregate business cycle moments in China, the US, and other OECD countries. The statistics confirm our observations above. In China, the relative volatility of employment is only 0.15 and the correlation of aggregate employment and output is close to zero, both of which are in contrast with the established business cycle facts for the developed economies that has been documented in e.g., Cooley and Prescott (1995). In Appendix B, we use alternative methods to detrend the data and show that the facts reported here are robust to alternative detrending methods.

Table 1: Aggregate Business Cycle Moments

\begin{tabular}{lccc}
\hline \hline & China & US & OECD average \\
\hline$\sigma(L) / \sigma(Y)$ & 0.15 & 0.75 & 0.69 \\
$\rho(L, Y)$ & -0.08 & 0.87 & 0.67 \\
\hline \hline
\end{tabular}

Note: $\sigma(x)$ is the standard deviation of variable $x . \rho(x, y)$ is the correlation of variable $x$ and $y . L$ and $Y$ are the aggregate employment (normalized by population) and GDP per capita, respectively. Variables are detrended using hp-filter with smoothing parameter of 100. 


\subsubsection{Employment Fluctuations at Sector Level}

The stark differences in the aggregate employment fluctuations between China and the developed countries conceal similarities at sector level. Panel (A) and (B) in Table 2 present the cyclical properties of the employments in the non-agricultural (na) and agricultural (a) sectors, respectively. For both China and the OECD countries, the volatility of sector employment relative to the volatility of sector GDP is high and employment is strongly pro-cyclical in the non-agricultural sector. In the agricultural sector, the relative volatility of employment is actually higher in China than in the OECD countries, and employment is acyclical in all the countries.

Table 2: Sector Moments

\begin{tabular}{lccc}
\hline \hline & China & US & OECD Average \\
(A) Non-Agriculture Sector & & & \\
\hline$\sigma\left(L_{n a}\right) / \sigma\left(Y_{n a}\right)$ & 0.73 & 0.75 & 0.73 \\
$\rho\left(L_{n a}, Y_{n a}\right)$ & 0.83 & 0.87 & 0.72 \\
& & & \\
$(\mathrm{~B})$ Agriculture Sector & & & \\
\hline$\sigma\left(L_{a}\right) / \sigma\left(Y_{a}\right)$ & 1.03 & 0.34 & 0.59 \\
$\rho\left(L_{a}, Y_{a}\right)$ & -0.39 & -0.10 & 0.08 \\
& & & \\
\hline \hline
\end{tabular}

Note: $\sigma(x)$ is the standard deviation of variable $x . \rho(x, y)$ is the correlation of variable $x$ and $y . L_{i}$ and $Y_{i}$ are the sector $i$ employment and output (normalized by population), $i \in\{a, n a\}$. Variables are detrended using hp-filter with smoothing parameter of 100.

Some may argue that the low volatility of aggregate employment in China is due to the unique institutional constraints that limit the employment variability. While it is true that there could be strong employment rigidity in the state-owned enterprises, the labour market for the non-state sector in China is quite flexible due to minimum regulations on hiring and firing workers by the non-state firms. Since the non-state sector employment is usually the margin at which aggregate employment adjusts over the business cycles, the institutional constraints on state-sector employment cannot explain the puzzle. Indeed, for the non-agricultural sector in China that includes the state-sector, the relative employment volatility is 0.73 , which is exactly 
the same as the OECD average of the ratio and close to the ratio of 0.75 in the US.

\subsubsection{Role of Structural Change in Employment Fluctuations}

The difference between China and the developed countries on the aggregate level reflects a more general phenomenon documented by Da-Rocha and Restuccia (2006) for 18 OECD countries: Aggregate employment is less volatile and less correlated with output in countries with a larger average share of employment in agriculture. However, it is important to note that the share of employment in agriculture is not constant over time within a country. In fact, it generally declines due to structural change. We now provide evidence that the degree of the co-movement between aggregate employment and output depends on the current share of employment in agriculture, not just the average share over a period of time.

In the baseline exercise, we run the following regression between aggregate employment and output using the cross-country data from the GGDC:

$$
\log L_{t}^{c j}=\beta_{1} \log Y_{t}^{c j}+\beta_{2} \log Y_{t}^{c j} \times l_{a t}^{j}+\beta_{3} l_{a t}^{j}+v^{j}+\xi_{t}+\varepsilon_{t}^{j}
$$

where $L_{t}^{c j}$ and $Y_{t}^{c j}$ are cyclical components of aggregate employment and output (both normalized by population) in country $j$ and year $t, l_{a t}^{j}$ is the current agriculture's share of employment in country $j$ and year $t$, and $v^{j}$ and $\xi_{t}$ are country and year fixed effects. Column (1) of Table 3 reports the regression result, which shows a significant negative coefficient of the interaction term $\log Y_{t}^{c j} \times l_{a, t}^{j}$. The result indicates that the correlation between aggregate employment and output declines with the current share of employment in agriculture. 
Table 3: Structural Change and Aggregate Employment Fluctuations

\begin{tabular}{lcc}
\hline \hline Dependent Variable: & $\log L_{t}^{c j}$ & $\log L_{t}^{c j}$ \\
\cline { 2 - 3 } & $(1)$ & $(2)$ \\
\hline $\log Y_{t}^{c j}$ & $0.434^{* * *}$ & $0.396^{* * *}$ \\
& $(0.094)$ & $(0.111)$ \\
$\log Y_{t}^{c j} \times l_{a, a v g}^{j}$ & & $-0.997^{* * *}$ \\
& & $(0.224)$ \\
$\log Y_{t}^{c j} \times\left(l_{a t}^{j}-l_{a, a v g}^{j}\right)$ & & $-1.287^{* * *}$ \\
& & $(0.367)$ \\
$\log Y_{t}^{c j} \times l_{a t}^{j}$ & $-1.060^{* * *}$ & \\
& $(0.196)$ & \\
$l_{a t}^{j}$ & 0.002 & 0.003 \\
Country Fixed Effect & $(0.020)$ & $(0.020)$ \\
Year Fixed Effect & $\mathrm{Y}$ & $\mathrm{Y}$ \\
$\mathrm{R}$-squared & $\mathrm{Y}$ & $\mathrm{Y}$ \\
Observations & 0.567 & 0.568 \\
\hline \hline
\end{tabular}

Note: The dependent variable is the aggregate employment in country $j$, year $t$. Aggregate employment and output are detrended using hp-filter with smoothing parameter of 100 to get their cyclic components, $L_{t}^{c j}$ and $Y_{t}^{c j} . l_{a, a v g}^{j}$ is the average share of employment in agriculture in country $j$ over the sample period. $l_{a t}^{j}$ is the current agriculture's share of employment in country $j$ and year $t$. The weighted least square uses countries' GDP as weights. Robust standard errors are reported in the parenthesis. ${ }^{*}$ denotes significance at the $90 \%$ confidence level, ${ }^{* *}$ denotes significance at the $95 \%$ confidence level, ${ }^{* * *}$ denotes significance at the $99 \%$ confidence level.

To illustrate that it is not just average agriculture employment share that matters, we present an alternative regression specification in equation (2) in which the output interacts with the average share of employment in agriculture $\left(l_{a, a v g}^{j}\right)$ and the difference between the current and average shares of employment in agriculture separately:

$\log L_{t}^{c j}=\beta_{1} \log Y_{t}^{c j}+\beta_{2} \log Y_{t}^{c j} \times l_{a, a v g}^{j}+\beta_{3} \log Y_{t}^{c j} \times\left(l_{a t}^{j}-l_{a, a v g}^{j}\right)+\beta_{4} l_{a t}^{j}+v^{j}+\xi_{t}+\varepsilon_{t}^{i}$.

Column (2) of Table 3 shows negative coefficient on the interaction term of av- 
erage agriculture employment share, which is in line with the fact documented in Da-Rocha and Restuccia (2006). Moreover, the coefficient on the interaction term $\log Y_{t}^{c j} \times\left(l_{a t}^{j}-l_{a, a v g}^{j}\right)$ is also negative and significant. This suggests that the current share of employment in agriculture is important in determining the correlation between aggregate employment and output, even after controlling for the average share. In both regressions, the coefficient on the current share of employment in agriculture itself is insignificant.

Given the strong interaction of the current share of employment in agriculture and the cyclic fluctuations of employment we just documented, it is important to have a model that can account for both the long-run structural change and short-run labour reallocation between sectors for countries like China, in which the share of employment in agriculture declines sharply from 1978 to 2017.

\subsubsection{Role of Income Effect in Employment Fluctuations}

It is well documented in the structural change literature that, in the long-run, a country's share of employment in agriculture is negatively related to its income. For example, Comin, Lashkari, and Mestieri (2020) emphasize the importance of income effect in understanding the structural change from agriculture to manufacturing and services. In Table 4, we report the correlation between the cyclical components of the relative employment in agriculture $\left(L_{a t} / L_{n a t}\right)$ and aggregate GDP per capita. The correlation is significantly negative for China, the US, the other OECD countries, and non-OECD countries. The evidence suggests that the income effect may also be important for labour reallocation between agriculture and the non-agricultural sectors over the business cycles.

Table 4: Income Effect over the Business Cycle

\begin{tabular}{ccccc}
\hline \hline & China & US & OECD Average & Non-OECD Average \\
\hline$\rho\left(L_{a} / L_{n a}, Y\right)$ & -0.83 & -0.68 & -0.50 & -0.33 \\
\hline \hline
\end{tabular}

Note: $\rho(x, y)$ is the correlation of variable $x$ and $y, L_{i}$ is the cyclic component of sector $i$ employment, $i \in\{a, n a\}$, and $Y$ is the cyclic component of aggregate GDP per capita, both of which are obtained by using the hp-filter with smoothing parameter of 100 . 
In summary, we have documented that employment fluctuations at sector level in China are similar to those in developed countries, that the aggregate employment fluctuations are affected by economic structure and structural change, and that reallocation of labour between agriculture and the non-agricultural sector is correlated with aggregate income. Motivated by these stylized facts, we next present our twosector model with income effect (non-homothetic preferences) that we will use to quantitatively account for labour market dynamics in both the long-run and shortrun in China.

\section{The Model}

There are two sectors indexed by $i=a$ and $n a$, representing agriculture and nonagriculture, respectively. Each sector produces a consumption good with a linear technology using labour as the only input:

$$
Y_{i t}=A_{i t} N_{i t}, \quad i=a, n a,
$$

where $Y_{i t}, A_{i t}$, and $N_{i t}$ are the output, labour productivity, and employment in sector $i$, respectively. There is a stand-in representative household whose preferences over a composite consumption good $C_{t}$ and working time $L_{t}$ are represented by the following utility function:

$$
U_{t}=C_{t}-\frac{B_{t}}{1+\sigma} L_{t}^{1+\sigma}
$$

Here, $\sigma$ is a non-negative number representing the inverse of the Frisch labour supply elasticity, and $B_{t}>0$ is a time-varying labour supply parameter that is used to capture the demographic factors (e.g., age structure and gender composition of the labour force) that affect average household's labour supply decisions. ${ }^{5}$ Following Hanoch (1975) and Comin, Lashkari, and Mestieri (2020), the composite consump-

\footnotetext{
${ }^{5}$ Note that when $B_{t}$ is a constant, our utility function is the same as the GHH utility function proposed by Greenwood, Hercowitz and Huffman (1988).
} 
tion $C_{t}$ is defined implicitly by the following equation:

$$
\left(\varphi_{a}\right)^{\frac{1}{\varepsilon}} C_{t}^{\frac{(1-\varepsilon) \mu_{a}}{\varepsilon}} c_{a t}^{\frac{\varepsilon-1}{\varepsilon}}+\left(\varphi_{n a}\right)^{\frac{1}{\varepsilon}} C_{t}^{\frac{(1-\varepsilon) \mu_{n a}}{\varepsilon}} c_{n a t}^{\frac{\varepsilon-1}{\varepsilon}}=1
$$

where $\varphi_{a}, \varphi_{n a}, \mu_{a}, \mu_{n a}$ and $\varepsilon$ are all positive constants. The parameter $\varphi_{i}$ represents the household's preference weight on consumption good in sector $i\left(\varphi_{a}+\varphi_{n a}=1\right)$, $\mu_{i}$ is a parameter that determines the income elasticity of consumption good $i$ and $\varepsilon$ is the elasticity of substitution between the two consumption goods. The implicit utility function is a generalization of the standard CES utility function by allowing for potentially different income elasticities for the two consumption goods. If $\mu_{a}=$ $\mu_{n a}=1$, then the utility function is reduced to the standard CES utility function. If $\varepsilon<1$ and $\mu_{a}<\mu_{n a}$, the income elasticity is smaller for the agricultural good than for the non-agricultural good, and therefore relative demand for the agricultural good declines with income.

\subsection{Social Planner's Problem}

Since we assume that there is no friction nor externality in the economy, the competitive allocation is the same as the social optimal allocation, which is the solution to the following social planner's problem:

$$
\max _{c_{a t}, c_{n a t}, L_{a t}, L_{n a t}, C_{t}}\left\{N_{t}\left[C_{t}-\frac{B_{t}}{1+\sigma} L_{t}^{1+\sigma}\right]\right\}
$$

subject to (3) and the following constraints:

$$
\begin{gathered}
c_{a t}=A_{a t} L_{a t}, \\
c_{n a t}=A_{n a t} L_{n a t}, \\
L_{a t}+L_{n a t}=L_{t} .
\end{gathered}
$$

Here, $N_{t}$ is the population size and $L_{i t}=N_{i t} / N_{t}$ is the ratio of employment in sector $i$ to total population $(i \in\{a, n a\})$. In the Appendix $\mathrm{C}$, we show that the optimal consumption of the two goods, $c_{a t}$ and $c_{n a t}$, and the aggregate employment rate $L_{t}$ 
satisfy the following equations:

$$
\begin{gathered}
c_{a t}=\frac{\varphi_{a} A_{a t}^{\varepsilon} C_{t}^{(1-\varepsilon) \mu_{a}}}{\left(\varphi_{a} A_{a t}^{\varepsilon-1} C_{t}^{(1-\varepsilon) \mu_{a}}+\varphi_{n a} A_{n a t}^{\varepsilon-1} C_{t}^{(1-\varepsilon) \mu_{n a}}\right)^{\frac{\varepsilon}{\varepsilon-1}}}, \\
c_{n a t}=\frac{\varphi_{n a} A_{n a t}^{\varepsilon} C_{t}^{(1-\varepsilon) \mu_{n a}}}{\left(\varphi_{a} A_{a t}^{\varepsilon-1} C_{t}^{(1-\varepsilon) \mu_{a}}+\varphi_{n a} A_{n a t}^{\varepsilon-1} C_{t}^{(1-\varepsilon) \mu_{n a}}\right)^{\frac{\varepsilon}{\varepsilon-1}}}, \\
L_{t}=\left[\frac{\left(\varphi_{a} A_{a t}^{\varepsilon-1} C_{t}^{(1-\varepsilon) \mu_{a}}+\varphi_{n a} A_{n a t}^{\varepsilon-1} C_{t}^{(1-\varepsilon) \mu_{n a}}\right)^{\frac{\varepsilon}{\varepsilon-1}}}{B_{t}\left(\mu_{a} \varphi_{a} A_{a t}^{\varepsilon-1} C_{t}^{(1-\varepsilon) \mu_{a}-1}+\mu_{n a} \varphi_{n a} A_{n a t}^{\varepsilon-1} C_{t}^{(1-\varepsilon) \mu_{n a}-1}\right)}\right]^{\frac{1}{\sigma}} .
\end{gathered}
$$

\subsection{Equilibrium Employment, Consumption, and Output}

From the goods market clearing conditions, (4), (5), (7), and (8), we have,

$$
\begin{aligned}
L_{a t} & =\frac{\varphi_{a} A_{a t}^{\varepsilon-1} C_{t}^{(1-\varepsilon) \mu_{a}}}{\left(\varphi_{a} A_{a t}^{\varepsilon-1} C_{t}^{(1-\varepsilon) \mu_{a}}+\varphi_{n a} A_{n a t}^{\varepsilon-1} C_{t}^{(1-\varepsilon) \mu_{n a}}\right)^{\frac{\varepsilon}{\varepsilon-1}}} \\
L_{n a t} & =\frac{\varphi_{n a} A_{n a t}^{\varepsilon-1} C_{t}^{(1-\varepsilon) \mu_{n a}}}{\left(\varphi_{a} A_{a t}^{\varepsilon-1} C_{t}^{(1-\varepsilon) \mu_{a}}+\varphi_{n a} A_{n a t}^{\varepsilon-1} C_{t}^{(1-\varepsilon) \mu_{n a}}\right)^{\frac{\varepsilon}{\varepsilon-1}}} .
\end{aligned}
$$

Hence the aggregate employment to population ratio is

$$
L_{t}=L_{a t}+L_{n a t}=\left(\varphi_{a} A_{a t}^{\varepsilon-1} C_{t}^{(1-\varepsilon) \mu_{a}}+\varphi_{n a} A_{n a t}^{\varepsilon-1} C_{t}^{(1-\varepsilon) \mu_{n a}}\right)^{\frac{1}{1-\varepsilon}}
$$

and the share of employment in agriculture is

$$
l_{a t} \equiv \frac{L_{a t}}{L_{t}}=\frac{\frac{\varphi_{a}}{1-\varphi_{a}}\left(\frac{A_{a t}}{A_{\text {nat }}}\right)^{\varepsilon-1} C_{t}^{(1-\varepsilon)\left(\mu_{a}-\mu_{n a}\right)}}{1+\frac{\varphi_{a}}{1-\varphi_{a}}\left(\frac{A_{a t}}{A_{\text {nat }}}\right)^{\varepsilon-1} C_{t}^{(1-\varepsilon)\left(\mu_{a}-\mu_{n a}\right)}},
$$


which is affected by two factors: the relative productivity of agriculture $A_{\text {at }} / A_{\text {nat }}$ and the aggregate consumption per capita $C_{t}$. The first factor represents the substitution effect and the second factor the income effect. In the special case of homothetic CES, when $\mu_{a}=\mu_{n a}$, the agriculture's share of employment is a function of the relative productivity $A_{a t} / A_{\text {nat }}$ only, and income effect is absent.

\subsection{Solving the Equilibrium}

Combining equations (12) and (9) yields the following equation for the equilibrium value of the aggregate consumption $C_{t}$ :

$$
C_{t}=B_{t} \frac{\mu_{a} \varphi_{a} A_{a t}^{\varepsilon-1} C_{t}^{(1-\varepsilon) \mu_{a}}+\mu_{n a} \varphi_{n a} A_{n a t}^{\varepsilon-1} C_{t}^{(1-\varepsilon) \mu_{n a}}}{\left[\varphi_{a} A_{a t}^{\varepsilon-1} C_{t}^{(1-\varepsilon) \mu_{a}}+\varphi_{n a} A_{n a t}^{\varepsilon-1} C_{t}^{(1-\varepsilon) \mu_{n a}}\right]^{\frac{\sigma+\varepsilon}{\varepsilon-1}}}
$$

Given the preference parameters and the real labour productivity of the two sectors, $A_{a t}$ and $A_{n a t}$, equation (14) can be used to solve for $C_{t}$. Given $C_{t}$, equations (10) and (11) can be used to solve for $L_{a t}$ and $L_{n a t}$. GDP per capita in the two sectors are then calculated as $Y_{a t}=A_{a t} L_{a t}$ and $Y_{n a t}=A_{n a t} L_{n a t}$, respectively. Finally, when the labour productivity levels are normalized so that the relative price of agriculture in some base year is 1, the aggregate real GDP per capita valued with base year prices is simply $Y_{t}=Y_{a t}+Y_{\text {nat }}{ }^{6}$

\section{Income and Price Effects on Labour Allocation}

In this section, we discuss how labour allocation between the two sectors are affected by income and relative prices in our model and provide empirical evidence on these two effects.

From equations (10) and (11), we can derive the following equation for the

\footnotetext{
${ }^{6}$ In the quantitative analysis, we use 2005 as the base year and $Y_{a t}, Y_{n a t}, A_{a t}$, and $A_{n a t}$ are all valued using 2005 international prices from the GGDC Productivity Level Database.
} 
relative employment:

$$
\ln \left(\frac{L_{a t}}{L_{n a t}}\right)=\ln \left(\frac{\varphi_{a}}{\varphi_{n a}}\right)-(1-\varepsilon) \ln \left(\frac{A_{a t}}{A_{n a t}}\right)-(1-\varepsilon)\left(\mu_{n a}-\mu_{a}\right) \ln C_{t}
$$

Productivities in the two sectors affect the relative employment through a substitution effect in the second term and an income effect in the third term. The value of the substitution elasticity, $\varepsilon$, and the relative magnitude of the two income elasticities, $\mu_{a}$ and $\mu_{n a}$, are important in determining how productivities in the two sectors affect the relative employment. For example, if $\varepsilon<1$, the relative employment of agriculture is negatively related to the relative productivity of agriculture, and if $\varepsilon<1$ and $\mu_{n a}>\mu_{a}$, the relative employment of agriculture is also a decreasing function of the aggregate consumption. Since labour productivities in both sectors have positive impact on the aggregate consumption, they both have a negative effect on the relative employment of agriculture through the income effect when $\varepsilon<1$ and $\mu_{n a}>\mu_{a}$.

Empirically, is $\varepsilon$ less than one and $\mu_{n a}$ greater than $\mu_{a}$ ? We now use the panel data from the GGDC 10-Sector Database to answer this question. As pointed out by Hanoch (1975) and Comin, Lashkari, and Mestieri (2020), substitution and income elasticities can be estimated using data on expenditures and prices. Let $E_{t}=p_{a t} Y_{a t}+p_{n a t} Y_{n a t}$ be the total expenditure per capita and $\omega_{i t}=p_{i t} Y_{i t} / E_{t}$ the expenditure share of sector $i, i=a, n a$. We prove in Appendix $\mathrm{C}$ that the following equation holds:

$$
\ln \left(\frac{\omega_{a t}}{\omega_{n a t}}\right)=\ln \left(\frac{\varphi_{a}}{\varphi_{n a}}\right)+(1-\varepsilon) \ln \left(\frac{p_{a t}}{p_{n a t}}\right)+(1-\varepsilon)\left(\mu_{a}-\mu_{n a}\right) \ln C_{t}
$$

The last term of equation (16) includes the aggregate consumption index $C_{t}$, which is not directly observed. However, we also prove in Appendix $\mathrm{C}$ that the following equation holds:

$$
(1-\varepsilon) \ln C_{t}=\frac{1}{\mu_{n a}}\left(-\ln \varphi_{n a}+\ln \omega_{n a t}+(1-\varepsilon) \ln \frac{E_{t}}{p_{n a t}}\right) .
$$


Substituting it into equation (16), then, yields the following $\ln \left(\frac{\omega_{a t}}{\omega_{n a t}}\right)=\ln \left(\frac{\varphi_{a}}{\varphi_{n a}^{\frac{\mu_{a}}{\mu_{a a}}}}\right)+(1-\varepsilon) \ln \left(\frac{p_{a t}}{p_{\text {nat }}}\right)+\left(\frac{\mu_{a}}{\mu_{n a}}-1\right)\left(\ln \omega_{\text {nat }}+(1-\varepsilon) \ln \frac{E_{t}}{p_{\text {nat }}}\right)$.

We can write the empirical counterpart of equation (17) as

$$
\ln \left(\frac{\omega_{a t}^{j}}{\omega_{\text {nat }}^{j}}\right)=\beta_{1} \ln \left(\frac{p_{a t}^{j}}{p_{\text {nat }}^{j}}\right)+\beta_{2} \ln \omega_{\text {nat }}^{j}+\beta_{1} \beta_{2} \ln \left(\frac{E_{t}^{j}}{p_{\text {nat }}^{j}}\right)+v_{j}+\zeta_{j t}
$$

where $\beta_{1}=1-\varepsilon, \beta_{2}=\mu_{a} / \mu_{n a}-1, j$ is an index for country, $v_{j}$ is a country fixed effect, ${ }^{7}$ and $\zeta_{j t}$ is the residual. Since the equation is log-linear in the observables, it should hold for the raw data, the hp-filtered trend data, and the hp-filtered cyclic data. In Table (5) we report our non-linear-least-square regression results using the raw, trend, and cyclic data in column (1) through (3), respectively. Since equation (17) should hold for domestic expenditures and since sector value-added $p_{i t} Y_{i t}$ may include net export of sector $i$, we also make adjustments to the expenditure data by subtracting sector nominal net export from sector value-added and total nominal net export from total value-added respectively. The results of the regressions using the adjusted expenditure data are reported in column (4)-(6).

In all the regressions we report in Table (5), the estimated value of $\beta_{1}$ is significantly positive and that of $\beta_{2}$ is significantly negative, which implies $\varepsilon<1$ and $\mu_{a} / \mu_{n a}<1$. Hence the empirical evidence suggests that the elasticity of substitution between the agricultural and non-agricultural consumption goods is less than one, and that income effect is important. Since the estimation results are similar whether we use trend or cyclic data, we conclude that income effect is important in both the long-run and short-run.

While our regression results here provide strong evidence for $\varepsilon<1$ and income effect, we recognize that the estimated values of the parameters could be biased due to potential endogeneity problems as, according to our model, $\ln \left(\omega_{a t} / \omega_{\text {nat }}\right)$,

\footnotetext{
${ }^{7}$ Like Comin, Lashkari and Mestieri (2020), we allow the preference weights $\varphi_{a}$ to vary by country, but restrict the elasticities to be identical across countries.
} 
$\ln \omega_{\text {nat }}$, and $\ln \left(E_{t} / p_{\text {nat }}\right)$ are all endogenously determined by the productivities in the two sectors, $A_{a t}$ and $A_{\text {nat }}$. Therefore, in Section 6 we will provide an alternative method that estimates these parameters structurally. The structural estimation in Section 6 also shows that $\varepsilon<1$ and $\mu_{n a}>\mu_{a}$.

\section{Employment Responses to Productivity Shocks}

We now discuss how productivity shocks affect employment when $\varepsilon<1$ and $\mu_{n a}>$ $\mu_{a}$. We first illustrate how the shares of the sector employment affect the responses of the aggregate consumption and employment to productivity shocks. We derive the following relationships from equation (12) and (14). The detailed derivations are shown in Appendix C.

$$
\begin{aligned}
d \ln C_{t} & =\frac{\left.\left[(\sigma+\varepsilon)\left(\mu_{a} l_{a t}+\mu_{n a} l_{\text {nat }}\right)+(1-\varepsilon) \mu_{a}\right]\right]_{a t} d \ln A_{a t}}{(\sigma+\varepsilon)\left(\mu_{a} l_{a t}+\mu_{n a} l_{\text {nat }}\right)^{2}+(1-\varepsilon)\left(\mu_{a}^{2} l_{a, t}+\mu_{a n}^{2} l_{\text {nat }}\right)-\left(\mu_{a} l_{a t}+\mu_{n a} l_{\text {nat }}\right)} \\
& +\frac{\left[(\sigma+\varepsilon)\left(\mu_{a} l_{a t}+\mu_{n a} l_{\text {nat }}\right)+(1-\varepsilon) \mu_{n a} l_{\text {nat }} d \ln A_{\text {nat }}\right.}{(\sigma+\varepsilon)\left(\mu_{a} l_{a t}+\mu_{n a} h_{n a t}\right)^{2}+(1-\varepsilon)\left(\mu_{a}^{2} l_{a t}+\mu_{n a}^{2} l_{\text {nat }}\right)-\left(\mu_{a} l_{a t}+\mu_{n a} l_{\text {nat }}\right)}
\end{aligned}
$$

and

$$
\begin{aligned}
& d \ln L_{t}=\frac{\left[\left(\mu_{a} l_{a t}+\mu_{n a} l_{n a t}\right)-(1-\varepsilon)\left(\mu_{n a}-\mu_{a}\right) \mu_{n a} l_{n a t}\right] l_{a t} d \ln A_{a t}}{(\sigma+\varepsilon)\left(\mu_{a} l_{a t}+\mu_{n a} l_{n a t}\right)^{2}+(1-\varepsilon)\left(\mu_{a}^{2} l_{a t}+\mu_{n a}^{2} l_{n a t}\right)-\left(\mu_{a} l_{a t}+\mu_{n a} l_{n a t}\right)} \\
& +\frac{\left[\left(\mu_{a} l_{a t}+\mu_{n a} l_{n a t}\right)+(1-\varepsilon)\left(\mu_{n a}-\mu_{a}\right) \mu_{a} l_{a t}\right] l_{\text {nat }} d \ln A_{n a t}}{(\sigma+\varepsilon)\left(\mu_{a} l_{a t}+\mu_{n a} l_{\text {nat }}\right)^{2}+(1-\varepsilon)\left(\mu_{a}^{2} l_{a t}+\mu_{n a}^{2} l_{\text {nat }}\right)-\left(\mu_{a} l_{a t}+\mu_{n a} l_{\text {nat }}\right)} .
\end{aligned}
$$

In the special case of homothetic CES, i.e., $\mu_{a}=\mu_{n a}=1$, the above equations are reduced to

$$
d \ln C_{t}=\left(1+\sigma^{-1}\right)\left(l_{a t} d \ln A_{a t}+l_{\text {nat }} d \ln A_{\text {nat }}\right),
$$

and

$$
d \ln L_{t}=\sigma^{-1}\left(l_{a t} d \ln A_{a t}+l_{\text {nat }} d \ln A_{\text {nat }}\right) .
$$

In this case, the responses of the aggregate employment and aggregate consumption to productivity shocks are perfectly correlated. Since aggregate consumption and aggregate output are highly correlated, it implies that the responses of aggregate employment and aggregate output are also highly correlated. Therefore, the homothetic model without income effect would not be able to match the low employment- 
output correlation we observe in the data for China.

However, when $\mu_{n a}>\mu_{a}$, the responses of the aggregate employment and aggregate consumption are no longer perfectly correlated. In fact, the responses of both aggregate variables depend on the economic structure at the time of the shock, which are the sector employment shares $l_{a t}$ and $l_{\text {nat }}$. This is consistent with the fact we presented in Table 3 of Section 2.2.3.

The volatility of the aggregate employment is also affected by the economic structure in the case of non-homothetic preferences. To see this clearly, consider the case of a sector neutral productivity shock, $d \ln A_{a t}=d \ln A_{n a t}=d z_{t}$, then, from (18) and (19), we have

$d \ln L_{t}=\frac{\left[\left(\mu_{a} l_{a t}+\mu_{n a} l_{n a t}\right)-(1-\varepsilon)\left(\mu_{n a}-\mu_{a}\right)^{2} l_{a t} l_{n a t}\right]}{(\sigma+\varepsilon)\left(\mu_{a} l_{a t}+\mu_{n a} l_{n a t}\right)^{2}+(1-\varepsilon)\left(\mu_{a}^{2} l_{a t}+\mu_{n a}^{2} l_{n a t}\right)-\left(\mu_{a} l_{a t}+\mu_{n a} l_{n a t}\right)} d z_{t}$.

When $\varepsilon<1$ and $\mu_{n a}>\mu_{a}$, the response of the aggregate employment to the productivity shock is reduced by the term $(1-\varepsilon)\left(\mu_{n a}-\mu_{a}\right)^{2} l_{a t} l_{n a t}$, which again depends on the values of $l_{a t}$ and $l_{n a t}$. This shows that the conditional variance of $d \ln L_{t}$ tends to be dampened when neither $l_{a t}$ nor $l_{\text {nat }}$ is close to zero. The unconditional variance of $d \ln L_{t}$, of course, is more complicated because employment shares are themselves endogenous variables affected by productivity shocks. To examine fully our model's implication for the aggregate employment fluctuations, we now turn to quantitative analysis.

\section{Quantitative Analysis}

We now examine quantitatively our model's implications for structural change and aggregate employment fluctuations. We first assume that there is no productivity shocks so that the labour productivities in both sectors are at the respective trend levels, and show that our calibrated model can quantitatively account for the secular decline of the agriculture's share of employment in China. We then introduce productivity shocks into the same calibrated model, and show that it can also quantitatively account for the labour reallocation between the two sectors and the aggregate 
employment fluctuations around the trend at the business cycle frequency.

The data we use for quantitative analysis are employment to population ratios and real GDP per capita in the agricultural and non-agricultural sectors, for both China and the US. The real GDPs are valued at the 2005 international prices using the price level data from the GGDC Productivity Level Database. The labour productivity $A_{i t}$ is the ratio of real GDP to employment in sector $i, i=a, n a$.

\subsection{Structural Change: Labour Reallocation in the Long-run}

We use the hp-filter to filter out the trends of the employment to population ratios in the two sectors and in the aggregate, and the labour productivities in the two sectors. Given the trend aggregate employment rate and trend labour productivities in the two sectors, we can see from equation (12) and (13) that both the trend of aggregate consumption and the trend of the share of employment in agriculture are determined by the four implicit utility function parameters, $\varphi_{a}, \varepsilon, \mu_{a}$ and $\mu_{n a}$. Therefore we can use the trend data in China to calibrate these parameters. Since the agriculture's share of employment is invariant with respect to the scale of the two income elasticity parameters, ${ }^{8} \mu_{a}$ and $\mu_{n a}$, we normalize the scale of the two parameters by setting $\mu_{a}$ to 1 . We discuss next our procedure of calibrating the remaining three parameters of the implicit utility function, $\varphi_{a}, \varepsilon$, and $\mu_{n a}$.

Let $\bar{x}_{t}$ denote the hp-filtered trend component of any variable $x_{t}$, and $T=40$ the number of years of our sample. First, for any $t=1, \ldots, T$, and given the trend aggregate employment rate $\bar{L}_{t}$ and trend labour productivities $\bar{A}_{a t}$ and $\bar{A}_{\text {nat }}$ in the data, from equation (12), we can solve the trend aggregate consumption $\bar{C}_{t}$ from the following equation,

$$
\bar{L}_{t}=\left(\varphi_{a}\left(\bar{A}_{a t}\right)^{\varepsilon-1}\left(\bar{C}_{t}\right)^{1-\varepsilon}+\left(1-\varphi_{a}\right)\left(\bar{A}_{n a t}\right)^{\varepsilon-1}\left(\bar{C}_{t}\right)^{(1-\varepsilon) \mu_{n a}}\right)^{\frac{1}{1-\varepsilon}}
$$

The solution defines the aggregate consumption as an implicit function of the three parameters, $\bar{C}_{t}\left(\varphi_{a}, \varepsilon, \mu_{n a}\right)$. Then, from (13), we can write the trend of the share of

\footnotetext{
${ }^{8}$ See a proof in Appendix D.
} 
employment in agriculture also as a function of $\left(\varphi_{a}, \varepsilon, \mu_{n a}\right)$,

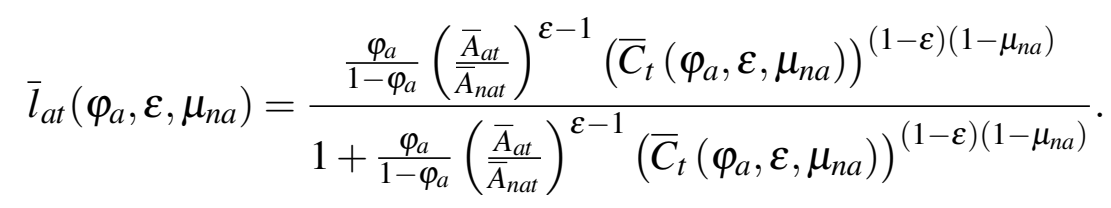

Finally, we use the non-linear least squares method to estimate the values of $\left(\varphi_{a}, \varepsilon, \mu_{n a}\right)$ by minimizing the following loss function:

$$
\sum_{t=1}^{T}\left\{\left[\bar{l}_{a t}\left(\varphi_{a}, \varepsilon, \mu_{n a}\right)-\bar{L}_{a t} / \bar{L}_{t}\right]^{2}\right\}
$$

where $\bar{L}_{a t}$ and $\bar{L}_{t}$ are the employment trends from the data. The estimation yields the following results for China: $\varphi_{a}=0.350$ with a $95 \%$ confidence interval of [0.319,0.380], $\varepsilon=0.197$ with a confidence interval of [0.086,0.307], and $\mu_{n a}=$ 3.678 with a confidence interval of $[3.019,4.338]$. We summarize the calibration results in Table 6 . The estimated value of the substitution elasticity $(\varepsilon)$ is less than one, implying that the substitution effect is such that the share of employment in agriculture is negatively related to the agriculture's relative productivity. This is consistent with the theoretical assumption of Ngai and Pissarides (2007) and the empirical finding of Herrendorf, Rogerson, and Valentinyi (2014). The estimated value of $\mu_{n a}$ is significantly larger than one, implying that the income effect plays an important role for the decline of the agriculture's share of employment. Over all, our structural estimation results are consistent with the reduced-form regression results using expenditure and price data which are reported in Section 4.

Figure 3 displays the trend of the agriculture's share of employment from the model and the data along with the trend of the relative labour productivity $\bar{A}_{a t} / \bar{A}_{\text {nat }}$ for both China and the US. The top left panel shows that our calibrated model matches well the trend of the agriculture's share of employment in China. For the US, we keep the values of the two elasticity parameters, $\varepsilon$ and $\mu_{n a}$, the same as the ones for China, but estimate $\varphi_{a}$ to match the model-implied average share of employment in agriculture to that in the US data. This yields a value of 0.116 for 
Table 6: Benchmark Calibration

\begin{tabular}{|c|c|c|c|c|}
\hline Parameter & Description & Target & China Value & US Value \\
\hline \multirow[t]{2}{*}{$\varphi_{a}$} & preference weight & average of agriculture & 0.350 & 0.116 \\
\hline & of agriculture & employment share & {$[0.319,0.380]$} & {$[0.113,0.119]$} \\
\hline \multirow[t]{2}{*}{$\varepsilon$} & elasticity of substitution & trend of agriculture & 0.197 & 0.197 \\
\hline & between two goods & $\begin{array}{l}\text { employment share } \\
\text { in China }\end{array}$ & {$[0.086,0.307]$} & {$[0.086,0.307]$} \\
\hline$\mu_{a}$ & $\begin{array}{l}\text { income elasticity } \\
\text { of agricultural good }\end{array}$ & normalization & 1 & 1 \\
\hline \multirow[t]{2}{*}{$\mu_{n a}$} & income elasticity & trend of agriculture & 3.678 & 3.678 \\
\hline & of non-agricultural good & $\begin{array}{l}\text { employment share } \\
\text { in China }\end{array}$ & {$[3.019,4.338]$} & {$[3.019,4.338]$} \\
\hline$\sigma$ & $\begin{array}{l}\text { inverse of Frisch elasticity } \\
\text { of labour supply }\end{array}$ & literature & 0.6 & 0.6 \\
\hline
\end{tabular}

Note: $95 \%$ confidence interval shown in square brackets.

$\varphi_{a}$ in the US. ${ }^{9}$ The top right panel of Figure 3 shows that our calibrated model also matches well the trend of the agriculture's share of employment in the US. In summary, using the same income and substitution elasticities for both countries and country-specific preference weight $\varphi_{a}$, our simple two-sector model with the non-homothetic CES utility function can quantitatively account for the structural changes in both China and the US. This result is consistent with the finding of Comin, Lashkari, and Mestieri (2020) for a panel of countries that does not include China.

Note that the income effect is crucial for our model's ability in matching the speed of structural change in both economies. To illustrate this, we set $\mu_{a}=\mu_{n a}=1$,

\footnotetext{
${ }^{9}$ The difference in the values of $\varphi_{a}$ does not necessarily mean that households in the two countries have different preferences. Rather, it may capture the potential differences in labour intensity of agricultural production, barriers to labour reallocation, and other factors that may influence the average share of employment in agriculture, but are abstracted from our model.
} 
Figure 3: Structural Change - China and the US
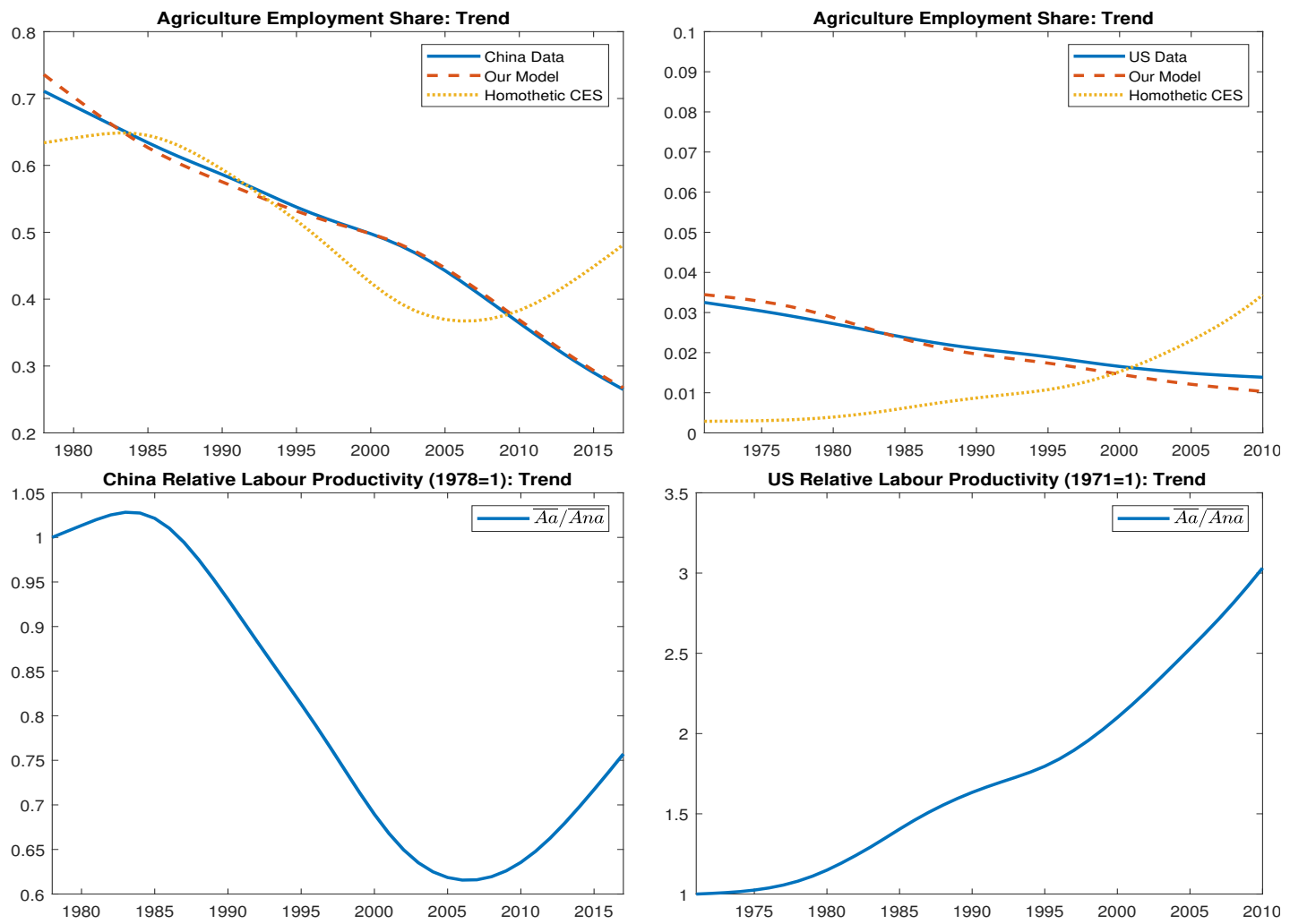

and recalibrate the values of $\varphi_{a}$ and $\varepsilon$ to minimize the same loss function in (22). The resulting value of $\varepsilon$ is 3.260, and the values of $\varphi_{a}$ are 0.973 for China and 0.021 for the US. We plot the model implied trend of the agriculture's share of employment for China and the US in the upper panel of Figure 3, labeled as homothetic CES. For both China and the US, the model without income effect performs poorly in matching the observed structural change. As can be seen clearly from equation (21), without income effect the structural change is purely driven by the change in the relative labour productivity $\bar{A}_{a t} / \bar{A}_{\text {nat }}$. If $\varepsilon>1$, the share of employment in agriculture is a strictly increasing function of the agriculture's relative labour productivity. However, in the case of China, the relative productivity is not changing monotonically over time. It increased between 1978 and 1983 (when an institutional reform in agriculture was carried out), decreased between 1983 and 2006, 
and then increased again after 2006 (when the non-agricultural sector's productivity growth slowed down). While the homothetic CES model can match the decline of the agriculture's share of employment between 1983 and 2006, it cannot generate the decline of the share between 1978-1983 and after 2006 without income effect. Since the US relative productivity has been growing during the sample period, the positive value of $\varepsilon$ also implies that the agriculture's share of employment would increase rather than decrease.

\subsection{Labour Reallocation in the Short-run and Aggregate Em- ployment Fluctuations}

We now turn to the cyclical properties of our model when there are shocks to the productivities in the two sectors. We use the same values of $\varphi_{a}, \varepsilon$, and $\mu_{n a}$ as the ones that are calibrated to match the long-run structural change in the data and reported in Table 6 . For the value of $\sigma$, we choose 0.6 so that the Frisch elasticity of labour supply is 1.7, a value used by Greenwood, Hercowitz, and Huffman (1988) and many others in the business cycle literature. We will show that our results are robust to alternative calibrations in Section 7.

Before presenting the quantitative results, we first discuss our strategy of dealing with the trend in the aggregate employment rate. As shown in Figure 4, due to the changes in the demographic factors such as age structure, the trend of aggregate employment rate is hump-shaped. Since the long-run trend of the aggregate employment rate is not the focus of our paper, we take it as given. Specifically, we choose the labour supply parameter $B_{t}$ to match the trend of aggregate employment rate using the equation below:

$$
\bar{L}_{t}=\left[\frac{\left(\varphi_{a}\left(\bar{A}_{a t}\right)^{\varepsilon-1}\left(\bar{C}_{t}\right)^{1-\varepsilon}+\left(1-\varphi_{a}\right)\left(\bar{A}_{n a t}\right)^{\varepsilon-1}\left(\bar{C}_{t}\right)^{(1-\varepsilon) \mu_{n a}}\right)^{\frac{\varepsilon}{\varepsilon-1}}}{B_{t}\left(\mu_{a} \varphi_{a}\left(\bar{A}_{a t}\right)^{\varepsilon-1}\left(\bar{C}_{t}\right)^{-\varepsilon}+\mu_{n a}\left(1-\varphi_{a}\right)\left(\bar{A}_{n a t}\right)^{\varepsilon-1}\left(\bar{C}_{t}\right)^{(1-\varepsilon) \mu_{n a}-1}\right)}\right]^{\frac{1}{\sigma}},
$$

where $\bar{L}_{t}, \bar{A}_{a t}$ and $\bar{A}_{n a t}$ are the trends of the aggregate employment rate, the labour productivity in the agricultural and non-agricultural sectors, respectively, and $\bar{C}_{t}$ is 
the trend aggregate consumption solved from equation (20).

Figure 4: Trend of Aggregate Employment Rate

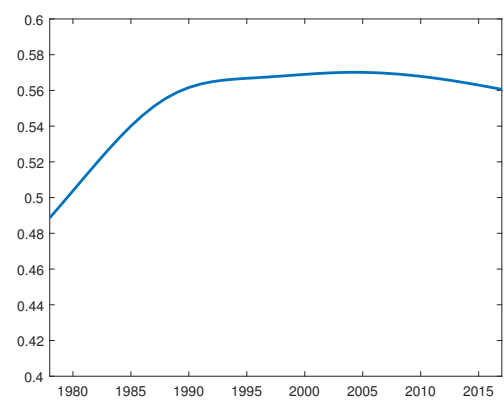

We are now ready to simulate the model and compute the business cycle moments. Specifically, we take as input the actual labour productivities $\left\{A_{a t}\right\}_{t=1, \ldots, T}$ and $\left\{A_{\text {nat }}\right\}_{t=1, \ldots, T}$ from the data, which include both the trend and the cyclical productivity shocks, and solve the sector-level and aggregate employment rates and GDP using the method described in Section 3.3. We then detrend the simulated variables from the model with hp-filter to retrieve the cyclic components and compute model-implied business cycle moments. The benchmark results are presented in Table 7.

\subsubsection{Benchmark Results}

The first and second columns of Table 7 present the business cycle statistics calculated from the Chinese data and the simulated time series from the model, and the third and fourth columns present the corresponding results for the US. Panel A shows the relative standard deviations of the aggregate employment to output and the correlation between the aggregate employment and output, Panel B the sector level correlations and relative standard deviations, Panel C the correlations of sector employments with the aggregate output and employment, and Panel D the correlation between sector employments and the correlations of the agriculture's relative employment with relative labour productivity and aggregate income per capita.

Results for China. Overall, the model does a good job in matching both the aggregate and sector moments in the Chinese data. From Panel A, we see that the 
model produces a relative aggregate employment volatility of 0.18 , which is very close to 0.15 in the data. The model also generates an acyclical employment series, with its correlation with output close to zero. From Panel B we see that the model generates relative employment volatilities in the two sectors that are comparable to those in the data. The model-implied sector employment-output correlation is strongly positive for the non-agricultural sector and negative for the agricultural sector, as in the data. Panel $\mathrm{C}$ shows the correlations of sector employments with aggregate output and employment. Consistent with the data, the model implied agricultural employment is strongly counter-cyclical and non-agricultural employment is strongly pro-cyclical. The correlation of the aggregate employment with the agricultural employment is positive in both the data and the model. The correlation of the aggregate employment with the non-agricultural employment, however, is negative in the model, but slightly positive in the data. In Section 7, we will show that this correlation is affected by export and investment demand, and that after introducing export and investment demand into the model, the implied correlation between aggregate and non-agricultural employment matches the data well. Finally, Panel D shows the labour reallocation between the two sectors. The correlation of employments in the two sectors is -0.82 in the model and -0.83 in the data, indicating strong reallocation between the two sectors. The last two rows in Panel D report correlations of relative employment with relative labour productivity and income. They are strongly negative in the model and data, suggesting that substitution and income effects are both important for labour reallocation over the business cycles in China.

Results for the US. Our model also does a good job in replicating the US business cycle facts. In the aggregate, the model generates highly pro-cyclical aggregate employment. The model produces a relative employment volatility that is lower than that in the data. This problem is common for standard real business cycle model, as pointed out by Cooley and Prescott (1995), that without additional labour market frictions these models have difficulty in generating sizable employment variations. Panel B and C report the within-sector employment-output correlations and the correlations of sector employment with the aggregate output and employment from the model. They are broadly consistent with the data. Panel D shows that 
the model is able to produce a negative correlation between sector employments and negative correlations of the agriculture's relative employment with the relative labour productivity and aggregate income per capita, which are also in line with the US data.

Table 7: Benchmark Results

\begin{tabular}{|c|c|c|c|c|}
\hline & \multicolumn{2}{|l|}{ China } & \multicolumn{2}{|l|}{ US } \\
\hline & Data & Model & Data & Model \\
\hline (A) & & & & \\
\hline$\sigma(L) / \sigma(Y)$ & 0.15 & 0.18 & 0.75 & 0.24 \\
\hline$\rho(L, Y)$ & -0.08 & -0.02 & 0.87 & 0.89 \\
\hline
\end{tabular}

(B)

\begin{tabular}{lcccc}
\hline$\sigma\left(L_{a}\right) / \sigma\left(Y_{a}\right)$ & 1.03 & 1.67 & 0.34 & 3.75 \\
$\sigma\left(L_{n a}\right) / \sigma\left(Y_{n a}\right)$ & 0.73 & 0.78 & 0.75 & 0.26 \\
$\rho\left(L_{a}, Y_{a}\right)$ & -0.39 & -0.80 & -0.10 & -0.96 \\
$\rho\left(L_{n a}, Y_{n a}\right)$ & 0.83 & 0.81 & 0.87 & 0.88
\end{tabular}

\begin{tabular}{lcccc}
$(\mathrm{C})$ & & & & \\
\hline$\rho\left(L_{a}, Y\right)$ & -0.73 & -0.57 & -0.27 & -0.17 \\
$\rho\left(L_{n a}, Y\right)$ & 0.84 & 0.79 & 0.87 & 0.89 \\
$\rho\left(L_{a}, L\right)$ & 0.35 & 0.75 & -0.09 & 0.02 \\
$\rho\left(L_{n a}, L\right)$ & 0.15 & -0.35 & 1.00 & 0.91
\end{tabular}

(D)

\begin{tabular}{lllll}
\hline$\rho\left(L_{a}, L_{n a}\right)$ & -0.83 & -0.82 & -0.12 & -0.38 \\
$\rho\left(L_{a} / L_{n a}, A_{a} / A_{n a}\right)$ & -0.67 & -0.91 & -0.27 & -0.99 \\
$\rho\left(L_{a} / L_{n a}, Y\right)$ & -0.83 & -0.72 & -0.68 & -0.22 \\
& & & & \\
\hline \hline
\end{tabular}

Note: $\sigma(x)$ is the standard deviation of variable $x . \rho(x, y)$ is the correlation of variable $x$ and $y . L$ and $Y$ are aggregate employment rate and output per capita. $L_{i}, Y_{i}$ and $A_{i}$ are sector employment, output, and labour productivity, where $i \in\{a, n a\}$. Variables are detrended using hp-filter with smoothing parameter of 100 .

Because of $\varepsilon<1$ and income effect, our model implies that the agricultural 
productivity has a very strong negative effect on agricultural employment. While the correlation between employment and output in the agricultural sector and the correlation between the relative employment and the relative labour productivities across the two sectors are indeed negative in the data, as predicted by the model, for both China and the US, the magnitude of the negative correlations are smaller than those implied by our model. We think this is probably due to the existence of ex post weather shocks that affect the measured agricultural output and labour productivity, but have no effect on employment in agriculture because the employment decisions have been made before the ex post weather shocks.

In summary, despite being highly stylized, our model can match well the employment fluctuations in both China and the US at sector level and in the aggregate. Similar to the case for the long-run structural change, the key to the success of our model is the income effect generated by the non-homothetic preferences. Because the income elasticity of the agricultural good is less than that of the nonagricultural good, the income effect on the employments in the agricultural and non-agricultural sectors are in the opposite directions. When the agricultural sector is large, this income-effect-induced negative correlation between employments in the two sectors dampens the aggregate employment volatility and reduces the correlation between the aggregate employment and output.

To further illustrate the importance of income effect, we next examine the quantitative implications of the two-sector model without income effect when the two consumption goods are aggregated by a standard homothetic CES utility function. We will show that the model can account neither the aggregate employment fluctuations nor labour reallocation between the two sectors over the business cycles in China.

\subsubsection{Comparison to Homothetic CES Model}

When $\mu_{a}=\mu_{n a}=1$, our model has the standard homothetic CES utility function, which is also the utility function used by Da-Rocha and Restuccia (2006). We have already shown in Section 6.1 that without income effect our calibration implies a value of 3.260 for $\varepsilon$, and the model cannot match the long-run structural change in the data for either China or the US. We now investigate the cyclical implications of 
this homothetic model. The results are reported as CES 1 in Table 8. In addition, we also use an alternative calibration strategy as in Da-Rocha and Restuccia (2006), which follows the common practice in the business cycle literature by detrending the data and focus on the cyclical moments in the calibration. We follow them by choosing a country-specific value of $\varphi_{a}$ to match the average share of employment in agriculture in the data for each of the two economies, and setting the value of $\varepsilon$ to 1.216 to match the ratio of the volatility of the agricultural employment to that of the non-agricultural employment in the US. The model simulation results based on this alternative calibration is reported as CES 2 in Table 8.

For the case of China, the model performs poorly in the aggregate level for both calibrations, with a model-implied employment-output correlation of 1 . This is in line with the analytical result we have in Section 5 that the model-implied aggregate employment and consumption are perfectly correlated. In this model with no investment, the aggregate output and the aggregate consumption are identical if the nominal GDP is deflated using the ideal price index. The real GDP (in the data and in our model) is slightly different because it is measured using the prices in a base year, but it is quantitatively very similar to the real GDP deflated using the ideal price index. So, it is not surprising that the correlation of the aggregate employment and the measured real aggregate GDP in the model is also one. Da-Rocha and Restuccia (2006) were able to generate a low correlation between the aggregate employment and output with a CES utility function, because they introduced independent ex post shocks to the agricultural productivity (weather shocks). In the version of the model without ex post shocks, their model's implied employmentoutput correlation is $0.95{ }^{10}$ It is slightly smaller than one because in their model there is investment so that output and consumption are not perfectly correlated. In contrast, our benchmark model with income effect can generate low employmentoutput correlation without introducing any ex post shocks.

The homothetic CES model without income effect also performs poorly at sector level. It implies that the agricultural employment is strongly pro-cyclical, but it is counter-cyclical in China and acyclical in the US. Moreover, the model implies that the relative employment of agriculture is positively correlated with both the

\footnotetext{
${ }^{10}$ See Table 9 on page 477 of Da-Rocha and Restuccia (2006).
} 


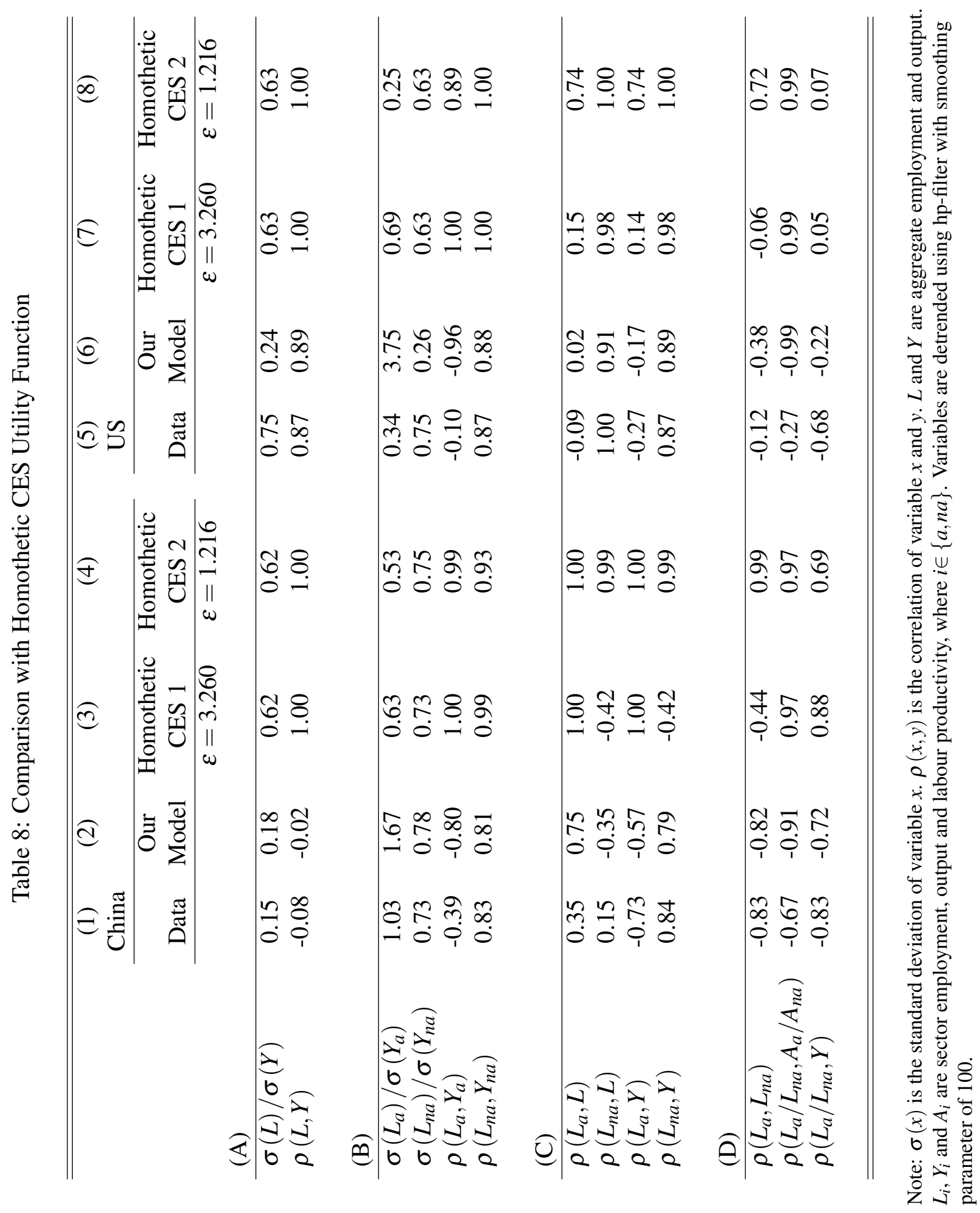


relative labour productivity of agriculture and aggregate GDP per capita, which is contradictory to the data for both China and the US.

\subsubsection{Variance Decomposition}

To further examine our model's performance in accounting for China's business cycle fluctuations, we compare the variance decomposition of output using both data and model simulated series. We run the following structural VAR for $\left(\triangle \ln A_{\text {nat }}, \triangle \ln A_{a t}, \triangle \ln Y_{t}\right)^{\prime}$,

$$
\left(\begin{array}{c}
\triangle \ln A_{\text {nat }} \\
\triangle \ln A_{a t} \\
\triangle \ln Y_{t}
\end{array}\right)=C+\left[\begin{array}{ccc}
f_{11} & f_{12} & 0 \\
f_{21} & f_{22} & 0 \\
f_{31} & f_{32} & f_{33}
\end{array}\right]\left(\begin{array}{c}
\triangle \ln A_{\text {nat }-1} \\
\triangle \ln A_{a t-1} \\
\triangle \ln Y_{t-1}
\end{array}\right)+\left[\begin{array}{ccc}
a_{11} & 0 & 0 \\
a_{21} & a_{22} & 0 \\
a_{31} & a_{32} & a_{33}
\end{array}\right]\left(\begin{array}{c}
\varepsilon_{\text {nat }} \\
\varepsilon_{a t} \\
\varepsilon_{y t}
\end{array}\right)
$$

where $C$ is a $3 \times 1$ vector of intercept term, and $\varepsilon_{t}$ is a $3 \times 1$ vector of zero-mean, serially uncorrelated shocks with a diagonal variance-covariance matrix. The structural identification restrictions we impose here are (a) the labour productivities are exogenous and not affected by output shock $\varepsilon_{y t}$, and (b) the non-agricultural labour productivity shock, $\varepsilon_{\text {nat }}$, affects contemporaneously all three variables, while the agricultural productivity shock, $\varepsilon_{a t}$, affects contemporaneously only agricultural labor productivity and output. Column (1) and (2) in Table 9 show the percentage of variance of the $k$-step-ahead forecast error in $\triangle \ln Y_{t}$ due to the non-agricultural and agricultural labour productivity shocks, respectively. In column (3) and (4), we perform the same variance decomposition exercise using the simulated output data from our model and find that the results are similar to those using the actual output data. In both decompositions, the fraction of output variance accounted for by the non-agricultural labour productivity shock is declining over time, while the fraction accounted for by the agricultural labour productivity shock is increasing over time. This is consistent with our model's implication that the agricultural labour productivity has a larger impact on labour reallocation away from agriculture through both substitution and income effect, and therefore has a more persistent impact on aggregate output through structural change. In contrast, the substitution and income effects of the non-agricultural labour productivity on structural change is 
in the opposite directions, and therefore the overall impact of the non-agricultural labour productivity on structural change is not as large as that of the agricultural labour productivity. Note that although the decomposition results show that the agricultural labour productivity shock contributes to a larger fraction of the variation in output than the non-agricultural labour productivity shock, this result is sensitive to the order of the recursive restrictions. In Appendix E where we order the agricultural labor productivity shock first, the variance decomposition shows that non-agricultural productivity shock accounts for a larger portion of the variation in output. However, under the alternative identification restriction, it is still true that the fraction of output variance accounted for by the non-agricultural labour productivity shock is declining over time, while the fraction accounted for by the agricultural labour productivity shock is increasing over time.

Table 9: Variance Decomposition of Aggregate Output

\begin{tabular}{lcccccc}
\hline \hline & \multicolumn{3}{c}{ Data } & & \multicolumn{2}{c}{ Model } \\
\cline { 2 - 3 } \cline { 5 - 6 } Forecast Horizon & $(1)$ & $\varepsilon_{n a}$ & $\varepsilon_{a}$ & & $\varepsilon_{n a}$ & $\varepsilon_{a}$ \\
\cline { 2 - 3 } \cline { 5 - 6 } & 0.30 & 0.49 & & 0.27 & 0.65 \\
& {$[0.06,0.54]$} & {$[0.26,0.71]$} & & {$[0.03,0.51]$} & {$[0.42,0.88]$} \\
& 0.22 & 0.56 & & 0.21 & 0.69 \\
3 & {$[-0.02,0.45]$} & {$[0.32,0.80]$} & & {$[-0.02,0.44]$} & {$[0.46,0.92]$} \\
& 0.19 & 0.58 & & 0.19 & 0.70 \\
4 & {$[-0.04,0.42]$} & {$[0.32,0.84]$} & & {$[-0.03,0.41]$} & {$[0.47,0.92]$} \\
& 0.18 & 0.59 & & 0.19 & 0.69 \\
& {$[-0.05,0.40]$} & {$[0.31,0.87]$} & & {$[-0.03,0.41]$} & {$[0.46,0.92]$} \\
\hline \hline
\end{tabular}

Note: $\varepsilon_{n a}$ denotes the non-agricultural labour productivity shock, $\varepsilon_{a}$ denotes the agricultural labour productivity shock. $95 \%$ confidence interval shown in square brackets.

\section{Sensitivity Analysis}

We now conduct several sensitivity analyses to show the robustness of our benchmark results.

Model with Trade and Investment. Since there is no international trade nor 
capital investment in our benchmark model, we have so far equated consumption to output for both the agricultural and non-agricultural sectors. With international trade and investment in the data, however, the consumption of agricultural good should equal the domestic output minus net export of the agricultural good, and the consumption of the non-agricultural good should equal the non-agricultural output minus net export of the non-agricultural good and investment. Instead of modeling trade and investment endogenously, we assume that the ratio of investment demand to non-agricultural output is exogenous, and that, for $i=a, n a$, the ratio of sector $i$ 's net export demand to sector $i$ 's output is also exogenous. These ratios are calculated directly from the Penn World Table 9.1 and the GGDC 10-Sector Database. A detailed description of the model with trade and investment is given in Appendix F.

We calibrate this model using the trend data in China and the same method as that for the benchmark model. The resulting values for $\varepsilon$ and $\mu_{n a}$ are 0.474 with a $95 \%$ confidence interval of $[0.389,0.560]$ and 5.709 with a $95 \%$ confidence interval of $[4.130,7.288]$, respectively. Figure 5 and Table 10 report the long-run and short-run properties of the model with trade and investment. They are largely consistent with the results from our benchmark model for both the structural change and business cycle fluctuations. Comparing to the benchmark model, the model with trade and investment matches the correlations between the aggregate employment and sector employments better for both China and the US, but generates a slightly higher correlation between the aggregate employment and output in China.

Figure 5: Structural Change: Model with Trade and Investment
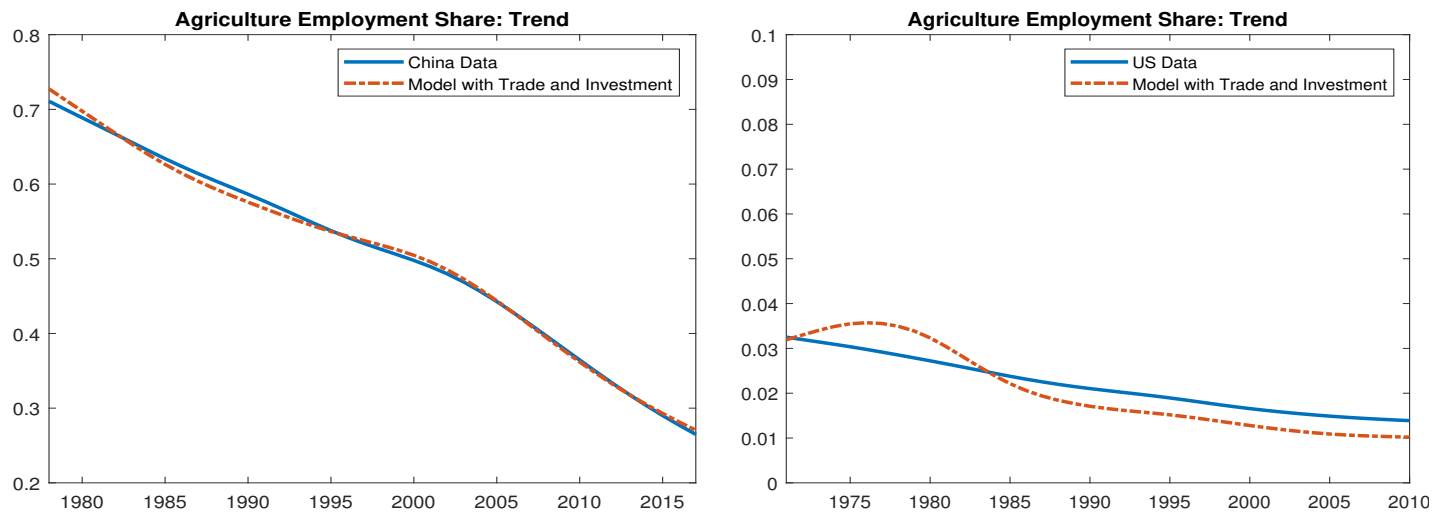
Table 10: Sensitivity Analysis I - China and the US

\begin{tabular}{|c|c|c|c|c|c|c|}
\hline & China & & & US & & \\
\hline & Data & Benchmark & $\begin{array}{l}\text { Model with } \\
\text { Trade and } \\
\text { Investment }\end{array}$ & Data & Benchmark & $\begin{array}{l}\text { Model with } \\
\text { Trade and } \\
\text { Investment }\end{array}$ \\
\hline (A) & & & & & & \\
\hline$\sigma(L) / \sigma(Y)$ & 0.15 & 0.18 & 0.10 & 0.75 & 0.24 & 0.21 \\
\hline$\rho(L, Y)$ & -0.08 & -0.02 & 0.25 & 0.87 & 0.89 & 0.80 \\
\hline (B) & & & & & & \\
\hline$\sigma\left(L_{a}\right) / \sigma\left(Y_{a}\right)$ & 1.03 & 1.67 & 1.29 & 0.34 & 3.75 & 1.46 \\
\hline$\sigma\left(L_{n a}\right) / \sigma\left(Y_{n a}\right)$ & 0.73 & 0.78 & 0.77 & 0.75 & 0.26 & 0.34 \\
\hline$\rho\left(L_{a}, Y_{a}\right)$ & -0.39 & -0.80 & -0.61 & -0.10 & -0.96 & 0.80 \\
\hline$\rho\left(L_{n a}, Y_{n a}\right)$ & 0.83 & 0.81 & 0.88 & 0.87 & 0.88 & 0.81 \\
\hline (C) & & & & & & \\
\hline$\rho\left(L_{a}, L\right)$ & 0.35 & 0.75 & 0.21 & -0.09 & 0.02 & -0.17 \\
\hline$\rho\left(L_{n a}, L\right)$ & 0.15 & -0.35 & 0.17 & 1.00 & 0.91 & 0.61 \\
\hline$\rho\left(L_{a}, Y\right)$ & -0.73 & -0.57 & -0.79 & -0.27 & -0.17 & -0.51 \\
\hline$\rho\left(L_{n a}, Y\right)$ & 0.84 & 0.79 & 0.89 & 0.87 & 0.89 & 0.77 \\
\hline (D) & & & & & & \\
\hline$\rho\left(L_{a}, L_{n a}\right)$ & -0.83 & -0.82 & -0.86 & -0.12 & -0.38 & -0.85 \\
\hline$\rho\left(L_{a} / L_{n a}, A_{a} / A_{n a}\right)$ & -0.67 & -0.91 & -0.70 & -0.27 & -0.99 & -0.69 \\
\hline$\rho\left(L_{a} / L_{n a}, Y\right)$ & -0.83 & -0.72 & -0.88 & -0.68 & -0.22 & -0.53 \\
\hline
\end{tabular}

Note: $\sigma(x)$ is the standard deviation of variable $x . \rho(x, y)$ is the correlation of variable $x$ and $y . L$ and $Y$ are aggregate employment and output. $L_{i}, Y_{i}$ and $A_{i}$ are sector employment, output and labour productivity, where $i \in\{a, n a\}$. Variables are detrended using hp-filter with smoothing parameter of 100 .

Expenditure Estimation. Instead of choosing the values of the parameters $\varphi_{a}, \varepsilon$, and $\mu_{n a}$ to fit the trend of the agriculture's share of employment in China, we now use equation (17) and the trend expenditure and price data for China to estimate the value of $\varepsilon$ and $\mu_{n a}$ (with $\mu_{a}$ normalized to 1 ). The results are $\varepsilon=0$ (the 
constraint $\varepsilon \geq 0$ binds, so confidence interval is not available), and $\mu_{n a}=2.889$ with a confidence interval of [2.819,2.958]. Given the estimated values of $\varepsilon$ and $\mu_{n a}$, we then choose the value of $\varphi_{a}$ so that the model implied average share of employment in agriculture matches that in the data. This results in a value of 0.297 for $\varphi_{a}$. The model implied structural change and cyclical moments are reported in Figure 6 and column (3) of Table (11). The model also matches the data well except that the aggregate employment-output correlation is slightly higher, 0.24 under this calibration, vs -0.02 in the benchmark case.

Figure 6: Structural Change: Expenditure Estimation
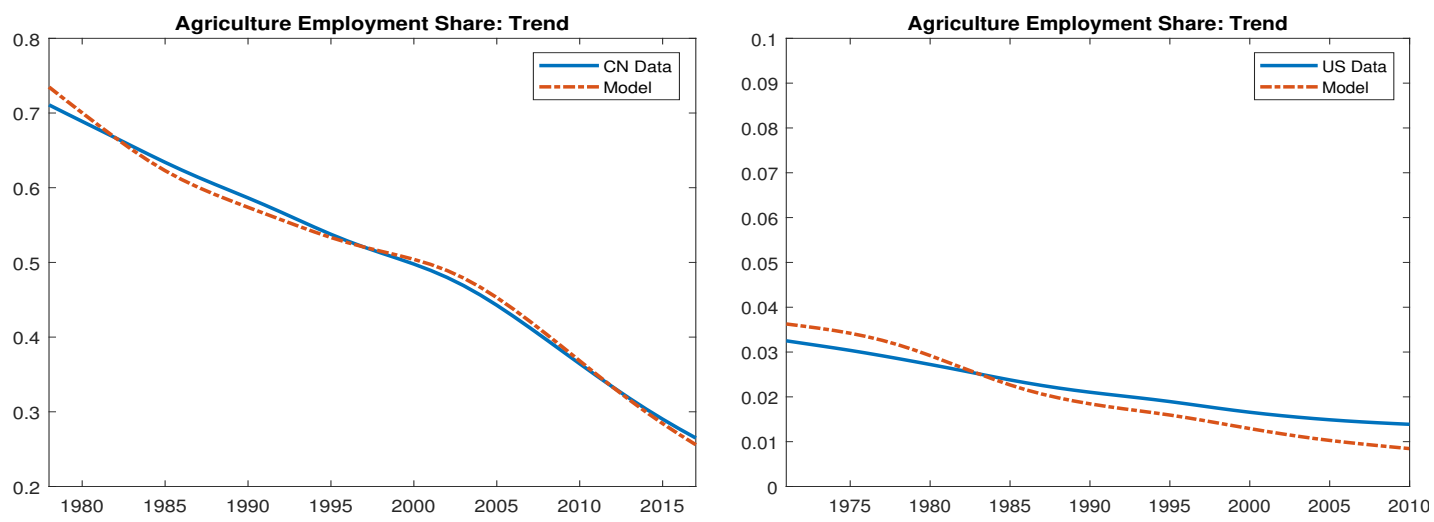

Cross-Country Estimation. In our benchmark calibration, we estimated the values of $\varepsilon$ and $\mu_{n a}$ to match the trend data on the agriculture's share of employment in China. We now use the same estimation method, but using the cross-country data to estimate these two parameters. Specifically, given the trend aggregate employment rate $\bar{L}_{t}^{j}$, the trend share of employment in agriculture $\bar{L}_{a t}^{j} / \bar{L}_{t}^{j}$, and the trend labour productivity $\bar{A}_{a t}^{j}$ and $\bar{A}_{n a t}^{j}$, for $j=1, \ldots, N$, where $N$ is the number of countries, we define $\bar{l}_{a t}^{j}\left(\varphi_{a}^{j}, \varepsilon, \mu_{n a}\right)$ as follows:

$$
\bar{l}_{a t}^{j}\left(\varphi_{a}^{j}, \varepsilon, \mu_{n a}\right)=\frac{\frac{\varphi_{a}^{j}}{1-\varphi_{a}}\left(\frac{\bar{A}_{a t}^{j}}{\bar{A}_{n a t}^{j}}\right)^{\varepsilon-1}\left(\bar{C}_{t}^{j}\right)^{(1-\varepsilon)\left(1-\mu_{n a}\right)}}{1+\frac{\varphi_{a}^{j}}{1-\varphi_{a}^{j}}\left(\frac{\bar{A}_{a t}^{j}}{\bar{A}_{n a t}^{j}}\right)^{\varepsilon-1}\left(\bar{C}_{t}^{j}\right)^{(1-\varepsilon)\left(1-\mu_{n a}\right)}},
$$




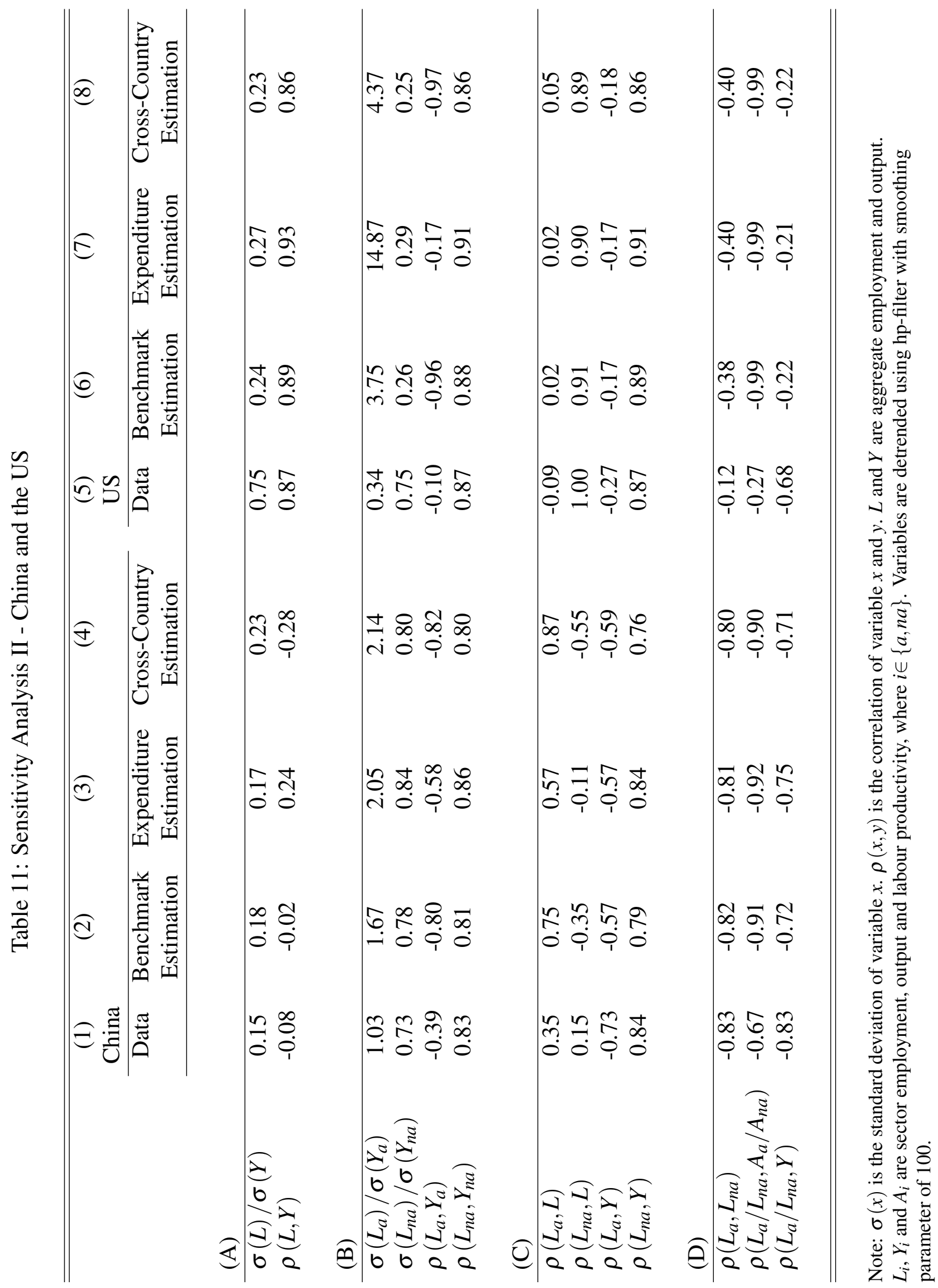


where $\bar{C}_{t}^{j}$ is the solution to the following equation:

$$
\bar{L}_{t}^{j}=\left(\varphi_{a}^{j}\left(\bar{A}_{a t}^{j}\right)^{\varepsilon-1}\left(\bar{C}_{t}^{j}\right)^{1-\varepsilon}+\left(1-\varphi_{a}^{j}\right)\left(\bar{A}_{n a t}^{j}\right)^{\varepsilon-1}\left(\bar{C}_{t}^{j}\right)^{(1-\varepsilon) \mu_{n a}}\right)^{\frac{1}{1-\varepsilon}}
$$

We choose $\varphi_{a}^{1}, \ldots, \varphi_{a}^{N}, \varepsilon$ and $\mu_{n a}$ to minimize the following loss function:

$$
\sum_{j=1}^{N} \sum_{t=1}^{T}\left\{\left[\bar{l}_{a t}^{j}\left(\varphi_{a}^{j}, \varepsilon, \mu_{n a}\right)-\bar{L}_{a t}^{j} / \bar{L}_{t}^{j}\right]^{2}\right\}
$$

The estimation gives $\varepsilon=0.175$ with a $95 \%$ confidence interval of $[0.143,0.206]$ and $\mu_{n a}=4.319$ with a $95 \%$ confidence interval of [4.140,4.499]. These estimates of $\varepsilon$ and $\mu_{n a}$ are not too different from the values we estimated using the Chinese data only in Section 6.1. Using these estimated values from the cross-country data, Figure 7 plots the model implied trend share of employment in agriculture for China and the US and compare them to those in the data. It can be seen that the model still does a good job in accounting for the structural change in both China and the US. Column (4) of Table 11 presents the business cycle moments of the model simulation using the cross-country estimates of the parameters. Again, the model does a good job in matching moments in the data.

Figure 7: Structural Change: Cross-Country Estimation
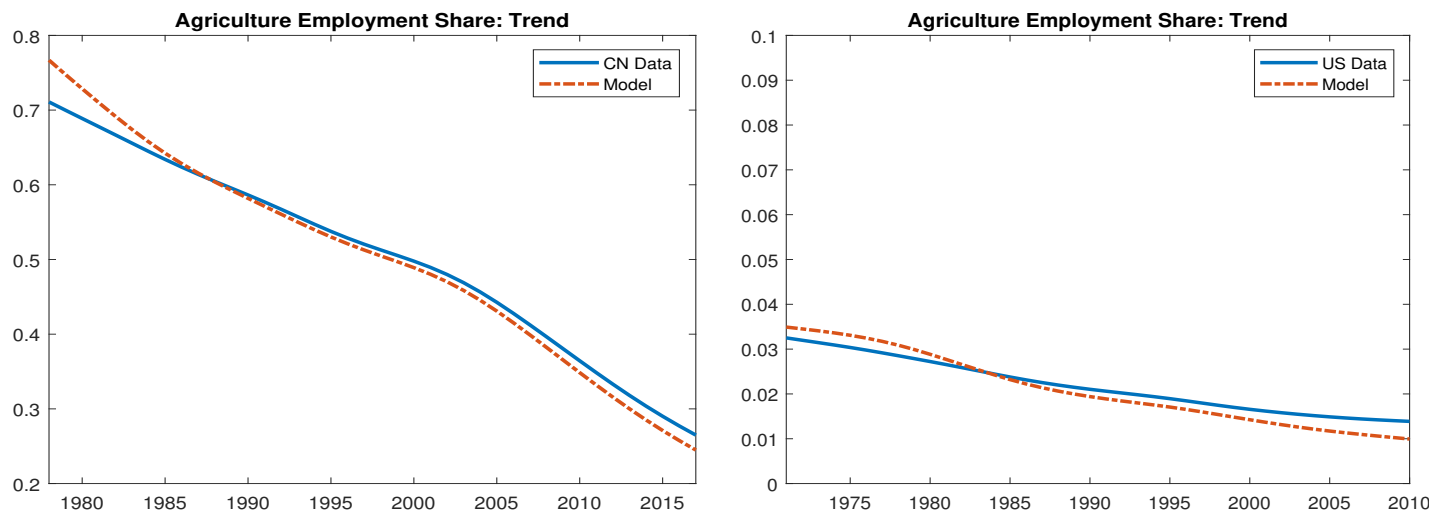

Elasticity of Labour Supply. The parameter $\sigma$ governs the elasticity of labour 
supply, which affects directly the aggregate employment volatility. In line with the literature, we choose this parameter to be 0.6 in our benchmark calibration. We now check the sensitivity of our model to this parameter by changing the value of $\sigma$. In column (3), (4), (8), (9) of Table 12, we report the simulation results for different values of $\sigma$ in China and the US. It can be seen that higher labour elasticity, or lower value of $\sigma$, implies higher aggregate employment volatility. Aggregate employment remains acyclical for China and pro-cyclical for the US under different values of $\sigma$. While there is some minor differences in the results across different value of $\sigma$, the properties of sector-level fluctuations and the labour reallocation between the two sectors of the benchmark model still hold.

Stochastic Shock Process. Our results are also robust to an alternative specification of the shock process. Instead of using the realized productivity shocks in the simulation, we now assume that the cyclical fluctuations of sector labour productivity shocks follow a VAR(1) process. We estimate the $\operatorname{VAR}(1)$ process from the data and simulate the economy. To save space, the estimation details are reported in Appendix G. Column (5) and (10) of Table 12 show the business cycle moments for China and the US. Both the aggregate and sector level implications from the benchmark model hold for this alternative specification.

In summary, we have conducted a series of sensitivity analysis in this section, including a model with trade and investment, two alternative calibrations, alternative parameter values for labour supply elasticity, and alternative productivity shock process. All sensitivity analyses yield results on structural change and employment fluctuation in China and the US that are very similar to the results from our benchmark model.

\section{Conclusion}

The cyclical behavior of aggregate employment differs significantly between China and developed countries. This sharp difference at the aggregate level conceals similar behavior of cyclical properties of employments at sector level. We argue that the main difference between China and the developed countries is the size of the 
agricultural sector, which results in quantitatively different impacts of labour reallocation between sectors on the aggregate employment dynamics. We show both empirically and theoretically that income effect plays an important role in determining the labour reallocation dynamics in both the long-run and short-run. Using a simple two-sector growth model with productivity shocks and non-homothetic preferences, we can simultaneously account for the structural change in the longrun and the employment fluctuations in the short-run in China. 


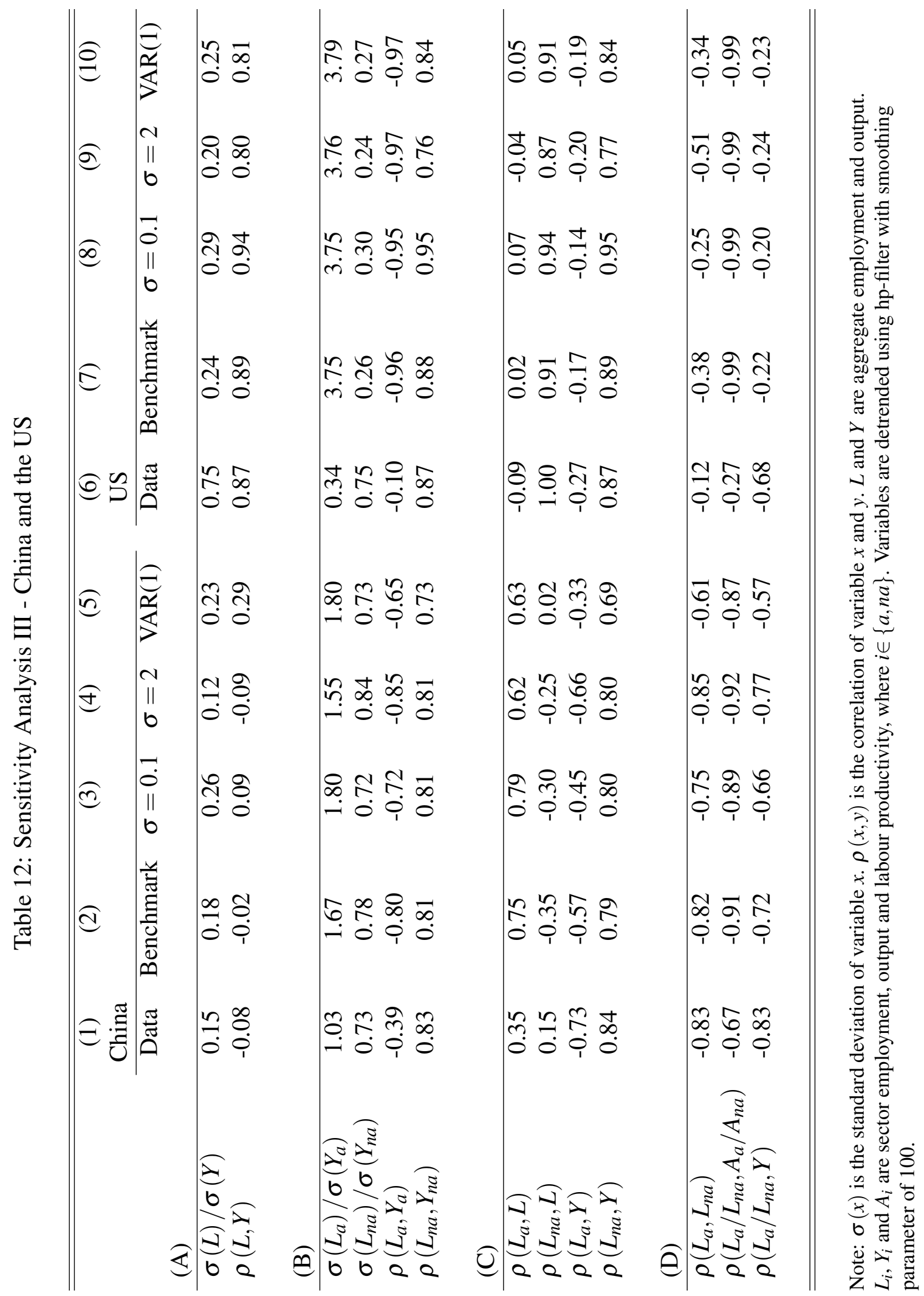




\section{Appendix}

\section{A Data Source}

The data used in this paper is obtained from the GGDC's 10-Sector Database (Timmer, de Vries and de Vries (2015)). This database reports annual sector-level data on real GDP (at constant 2005 national prices) and employment (persons engaged) for a wide coverage of regions, including Sub-Saharan Africa, Middle East and North Africa, Asia, Latin America, North America and Europe. The list of 40 countries are Argentina (1972-2011), Bolivia (1971-2010), Botswana (19712010), Chile (1972-2011), China (1978-2017), Colombia (1971-2010), Costa Rica (1972-2011), Denmark (1970-2009), Egypt (1973-2012), Spain (1970-2009), Ethiopia (1972-2011), France (1970-2009), United Kingdom (1970-2009), Ghana (1972-2011), Hong Kong (1974-2011), Indonesia (1973-2012), India (1971-2010), Italy (1970-2009), Japan (1972-2011), Kenya (19722011), South Korea (1971-2010), Mexico (1972-2011), Morocco (1973-2012), Mauritius (19722011), Malawi (1971-2010), Malaysia (1975-2011), Nigeria (1972-2011), Netherlands (19702009), Peru (1972-2011), Philippines (1973-2012), Senegal (1971-2010), Singapore (1972-2011), Sweden (1970-2009), Thailand (1973-2012), Taiwan (1973-2012), Tanzania (1972-2011), US (1971-2010), Venezuela (1972-2011), South Africa (1972-2011), and Zambia (1971-2010). Among these, we have 12 OECD countries: Chile, Denmark, Spain, France, UK, Italy, Japan, South Korea, Mexico, Netherlands, Sweden and the US. The cross-country facts are computed based on the sample period in the brackets. For our quantitative analysis of China and the US, we convert the real GDP in 2005 national prices to real GDP in 2005 international prices using the price level data from the GGDC Productivity Level Database.

For countries other than China, we directly use data from the GGDC and aggregate the nine sectors outside agriculture into one non-agricultural sector. For China, the 10-Sector Database uses the official employment series from China's National Bureau of Statistics (NBS) that are published in the annual China Statistical Yearbook. However, as pointed out by Holz (2006) and Brandt and Zhu (2010), there is a serious problem with the National Bureau of Statistics' total employment serie that needs to be dealt with. Hence, we construct revised annual employment series for China as described in Section 2.

\section{B Robustness of Facts}

In Table 13 we show that our facts are robust to different filtering methods. In particular, we compute the business cycle moments from the Baxter-King filter, which defines business cycle as the cyclical components between 2 and 8 years. The business cycle moments from the Baxter-King filter are very close to those from the hp- filter. 


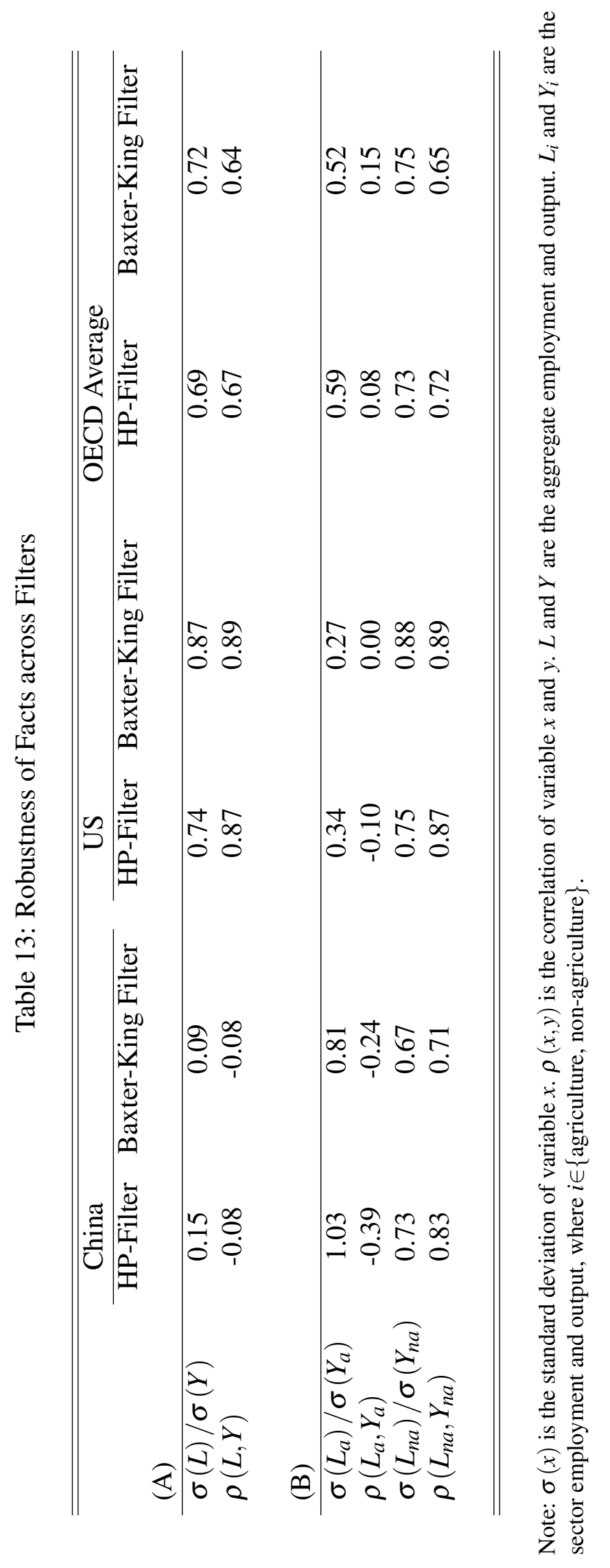




\section{Derivation of Formulas}

Equations in Section 3.1. The FOCs of the social planner's maximization problem with respect to $L_{a t}$ and $L_{n a t}$ are:

$$
\begin{gathered}
\frac{\partial C_{t}}{\partial c_{a t}} C_{t}^{-1} A_{a t}-B_{t} L_{t}^{\sigma}=0 \\
\frac{\partial C_{t}}{\partial c_{n a t}} C_{t}^{-1} A_{n a t}-B_{t} L_{t}^{\sigma}=0
\end{gathered}
$$

From equation (3), we have

$$
\begin{gathered}
\mu_{a}\left(\varphi_{a}\right)^{\frac{1}{\varepsilon}} c_{a t}^{\frac{\varepsilon-1}{\varepsilon}} C_{t}^{\frac{(1-\varepsilon) \mu_{a}-\varepsilon}{\varepsilon}} \frac{\partial C_{t}}{\partial c_{a t}}+\mu_{n a}\left(\varphi_{n a}\right)^{\frac{1}{\varepsilon}} c_{n a t}^{\frac{\varepsilon-1}{\varepsilon}} C_{t}^{\frac{(1-\varepsilon) \mu_{n a}-\varepsilon}{\varepsilon}} \frac{\partial C_{t}}{\partial c_{a t}} \\
-\left(\varphi_{a}\right)^{\frac{1}{\varepsilon}} c_{a t}^{-\frac{1}{\varepsilon}} C_{t}^{\frac{(1-\varepsilon) \mu_{a}}{\varepsilon}}=0, \\
\mu_{a}\left(\varphi_{a}\right)^{\frac{1}{\varepsilon}} c_{a t}^{\frac{\varepsilon-1}{\varepsilon}} C_{t}^{\frac{(1-\varepsilon) \mu_{a}-\varepsilon}{\varepsilon}} \frac{\partial C_{t}}{\partial c_{n a t}}+\mu_{n a}\left(\varphi_{n a}\right)^{\frac{1}{\varepsilon}} c_{n a t}^{\frac{\varepsilon-1}{\varepsilon}} C_{t}^{\frac{(1-\varepsilon) \mu_{n a-\varepsilon}}{\varepsilon}} \frac{\partial C_{t}}{\partial c_{n a t}} \\
-\left(\varphi_{n a}\right)^{\frac{1}{\varepsilon}} c_{n a t}^{-\frac{1}{\varepsilon}} C_{t}^{\frac{(1-\varepsilon) \mu_{n a}}{\varepsilon}}=0 .
\end{gathered}
$$

Thus, we have

$$
\begin{aligned}
\frac{\partial C_{t}}{\partial c_{a t}} & =\frac{\left(\varphi_{a}\right)^{\frac{1}{\varepsilon}} c_{a t}^{-\frac{1}{\varepsilon}} C_{t}^{\frac{(1-\varepsilon) \mu_{a}}{\varepsilon}}}{D_{t}} \\
\frac{\partial C_{t}}{\partial c_{n a t}} & =\frac{\left(\varphi_{n a}\right)^{\frac{1}{\varepsilon}} c_{n a t}^{-\frac{1}{\varepsilon}} C_{t}^{\frac{(1-\varepsilon) \mu_{n a}}{\varepsilon}}}{D_{t}}
\end{aligned}
$$

where

$$
D_{t}=\mu_{a}\left(\varphi_{a}\right)^{\frac{1}{\varepsilon}} c_{a t}^{\frac{\varepsilon-1}{\varepsilon}} C_{t}^{\frac{(1-\varepsilon) \mu_{a}-\varepsilon}{\varepsilon}}+\mu_{n a}\left(\varphi_{n a}\right)^{\frac{1}{\varepsilon}} c_{n a t}^{\frac{\varepsilon-1}{\varepsilon}} C_{t}^{\frac{(1-\varepsilon) \mu_{n a}-\varepsilon}{\varepsilon}},
$$

Substituting equations (27) and (28) into (25) and (26), respectively, and solving for $c_{a t}$ and $c_{n a t}$, we have the following:

$$
\begin{aligned}
c_{a t} & =\varphi_{a}\left(\frac{A_{a t}}{D_{t} B_{t} L_{t}^{\sigma} C_{t}}\right)^{\varepsilon} C_{t}^{(1-\varepsilon) \mu_{a}}, \\
c_{n a t} & =\varphi_{n a}\left(\frac{A_{n a t}}{D_{t} B_{t} L_{t}^{\sigma} C_{t}}\right)^{\varepsilon} C_{t}^{(1-\varepsilon) \mu_{n a}} .
\end{aligned}
$$

Substituting these two equations into (3) we have

$$
\varphi_{a}\left(\frac{A_{a t}}{D_{t} B_{t} L_{t}^{\sigma} C_{t}}\right)^{\varepsilon-1} C_{t}^{(1-\varepsilon) \mu_{a}}+\varphi_{n a}\left(\frac{A_{n a t}}{D_{t} B_{t} L_{t}^{\sigma} C_{t}}\right)^{\varepsilon-1} C_{t}^{(1-\varepsilon) \mu_{n a}}=1,
$$


which implies that

$$
\begin{gathered}
\left(D_{t} B_{t} L_{t}^{\sigma} C_{t}\right)^{1-\varepsilon}\left(\varphi_{a} A_{a t}^{\varepsilon-1} C_{t}^{(1-\varepsilon) \mu_{a}}+\varphi_{n a} A_{n a t}^{\varepsilon-1} C_{t}^{(1-\varepsilon) \mu_{n a}}\right)=1 \\
D_{t} B_{t} L_{t}^{\sigma} C_{t}=\left(\varphi_{a} A_{a t}^{\varepsilon-1} C_{t}^{(1-\varepsilon) \mu_{a}}+\varphi_{n a} A_{n a t}^{\varepsilon-1} C_{t}^{(1-\varepsilon) \mu_{n a}}\right)^{\frac{1}{\varepsilon-1}} .
\end{gathered}
$$

Substituting (32) into (30) and (31) and solving for $c_{a t}$ and $c_{\text {nat }}$ yield the solution in equations (7) and (8). Substituting (7) and (8) into (29) and simplifying yields the following:

$$
D_{t}=\frac{\mu_{a} \varphi_{a} A_{a t}^{\varepsilon-1} C_{t}^{(1-\varepsilon) \mu_{a}-1}+\mu_{n a} \varphi_{n a} A_{n a t}^{\varepsilon-1} C_{t}^{(1-\varepsilon) \mu_{n a}-1}}{\varphi_{a} A_{a t}^{\varepsilon-1} C_{t}^{(1-\varepsilon) \mu_{a}}+\varphi_{n a} A_{n a t}^{\varepsilon-1} C_{t}^{(1-\varepsilon) \mu_{n a}}}
$$

From (32), then, we have

$$
L_{t}=\left[\frac{\left(\varphi_{a} A_{a t}^{\varepsilon-1} C_{t}^{(1-\varepsilon) \mu_{a}}+\varphi_{n a} A_{n a t}^{\varepsilon-1} C_{t}^{(1-\varepsilon) \mu_{n a}}\right)^{\frac{\varepsilon}{\varepsilon-1}}}{B_{t}\left(\mu_{a} \varphi_{a} A_{a t}^{\varepsilon-1} C_{t}^{(1-\varepsilon) \mu_{a}-1}+\mu_{n a} \varphi_{n a} A_{n a t}^{\varepsilon-1} C_{t}^{(1-\varepsilon) \mu_{n a}-1}\right)}\right]^{\frac{1}{\sigma}}
$$

Equation (17) in Section 4. Given the total expenditure $E_{t}$, the household's problem is

$$
\max _{c_{a t}, c_{n a t}} C_{t}\left(c_{a t}, c_{n a t}\right)
$$

subject to

$$
p_{a t} c_{a t}+p_{\text {nat }} c_{\text {nat }}=E_{t} .
$$

Similar to the derivation for the social planner's problem above, we can show that the expenditure on good in sector $i, E_{i}$, is given by the following equation:

$$
E_{i t}=p_{i t} c_{i t}=\frac{\varphi_{i} p_{i t}^{1-\varepsilon} C_{t}^{(1-\varepsilon) \mu_{i}}}{\varphi_{a} p_{a t}^{1-\varepsilon} C_{t}^{(1-\varepsilon) \mu_{a}}+\varphi_{n a} p_{n a t}^{1-\varepsilon} C_{t}^{(1-\varepsilon) \mu_{n a}}} E_{t}, i=a, n a .
$$

From the definition of $C_{t}$, we have

$$
\left(\varphi_{a} p_{a t}^{1-\varepsilon} C_{t}^{(1-\varepsilon) \mu_{a}}+\varphi_{n a} p_{n a t}^{1-\varepsilon} C_{t}^{(1-\varepsilon) \mu_{n a}}\right)\left(\frac{E_{t}}{\varphi_{a} p_{a t}^{1-\varepsilon} C_{t}^{(1-\varepsilon) \mu_{a}}+\varphi_{n a} p_{n a t}^{1-\varepsilon} C_{t}^{(1-\varepsilon) \mu_{n a}}}\right)^{\frac{\varepsilon-1}{\varepsilon}}=1
$$

which implies that

$$
\varphi_{a} p_{a t}^{1-\varepsilon} C_{t}^{(1-\varepsilon) \mu_{a}}+\varphi_{n a} p_{n a t}^{1-\varepsilon} C_{t}^{(1-\varepsilon) \mu_{n a}}=E_{t}^{1-\varepsilon}
$$

Therefore, we have

$$
p_{i t} c_{i t}=\varphi_{i} p_{i t}^{1-\varepsilon} C_{t}^{(1-\varepsilon) \mu_{i}} E_{t}^{\varepsilon}
$$


Solving for $C_{t}^{1-\varepsilon}$,

$$
C_{t}^{1-\varepsilon}=\left(\varphi_{i}^{-1} p_{i t}^{\varepsilon-1} \frac{E_{i t}}{E_{t}^{\varepsilon}}\right)^{\frac{1}{\mu_{i}}}=\left(\varphi_{i}^{-1} \frac{E_{i t}}{E_{t}} \frac{E_{t}^{1-\varepsilon}}{p_{i t}^{1-\varepsilon}}\right)^{\frac{1}{\mu_{i}}}
$$

Therefore, we have

$$
(1-\varepsilon) \ln C_{t}=\frac{1}{\mu_{i}}\left(-\ln \varphi_{i}+\ln \frac{E_{i t}}{E_{t}}+(1-\varepsilon) \ln \frac{E_{t}}{p_{i t}}\right)
$$

From the equation for $E_{i t}$, we have

$$
\ln \frac{\omega_{a t}}{\omega_{\text {nat }}}=\ln \frac{E_{a t}}{E_{\text {nat }}}=\ln \frac{\varphi_{a}}{\varphi_{\text {na }}}+(1-\varepsilon) \ln \frac{p_{a t}}{p_{\text {nat }}}+(1-\varepsilon)\left(\mu_{a}-\mu_{n}\right) \ln C_{t} .
$$

Combining the two equations, we have

$$
\ln \frac{\omega_{a t}}{\omega_{n a t}}=\ln \left(\frac{\varphi_{a}}{\varphi_{n a}} \varphi_{i}^{\frac{\mu_{n}-\mu_{a}}{\mu_{i}}}\right)+(1-\varepsilon) \ln \frac{p_{a t}}{p_{n a t}}-\left(\frac{\mu_{n a}-\mu_{a}}{\mu_{i}}\right) \ln \omega_{i t}-(1-\varepsilon)\left(\frac{\mu_{n a}-\mu_{a}}{\mu_{i}}\right) \ln \frac{E_{t}}{p_{i t}}
$$

Equation (17) is the case when $i=n a$.

Equations in Section 5. Taking the logarithmic of equations (14) and (12), we have

$$
\begin{aligned}
\ln C & =\ln B+\frac{\sigma+\varepsilon}{1-\varepsilon} \ln \left[\varphi_{a} A_{a}^{\varepsilon-1} C^{(1-\varepsilon) \mu_{a}}+\varphi_{n a} A_{n a}^{\varepsilon-1} C^{(1-\varepsilon) \mu_{n a}}\right] \\
& +\ln \left[\mu_{a} \varphi_{a} A_{a}^{\varepsilon-1} C^{(1-\varepsilon) \mu_{a}}+\mu_{n a} \varphi_{n a} A_{n a}^{\varepsilon-1} C^{(1-\varepsilon) \mu_{n a}}\right] \\
\ln L & =\frac{1}{1-\varepsilon} \ln \left[\varphi_{a} A_{a}^{\varepsilon-1} C^{(1-\varepsilon) \mu_{a}}+\varphi_{n a} A_{n a}^{\varepsilon-1} C^{(1-\varepsilon) \mu_{n a}}\right]
\end{aligned}
$$

Note that $d x^{a}=a x^{a-1} d x=a x^{a} d \ln x$ for any $a$. Differentiating (34) and (35) we have

$$
\begin{aligned}
& d \ln C=\quad-\frac{(\sigma+\varepsilon) \varphi_{a} A_{a}^{\varepsilon-1} C^{(1-\varepsilon) \mu_{a}} d \ln A_{a}}{\varphi_{a} A_{a}^{\varepsilon-1} C^{(1-\varepsilon) \mu_{a}}+\varphi_{n a} A_{n a}^{\varepsilon-1} C^{(1-\varepsilon) \mu_{n a}}}-\frac{(\sigma+\varepsilon) \varphi_{n a} A_{n a}^{\varepsilon-1} C^{(1-\varepsilon) \mu_{n a}} d \ln A_{n a}}{\varphi_{a} A_{a}^{\varepsilon-1} C^{(1-\varepsilon) \mu_{a}}+\varphi_{n a} A_{n a}^{\varepsilon-1} C^{(1-\varepsilon) \mu_{n a}}}
\end{aligned}
$$

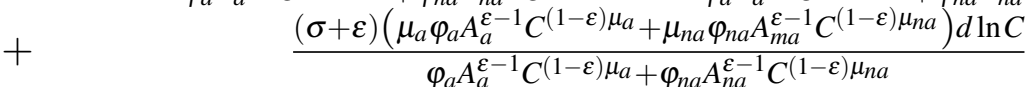

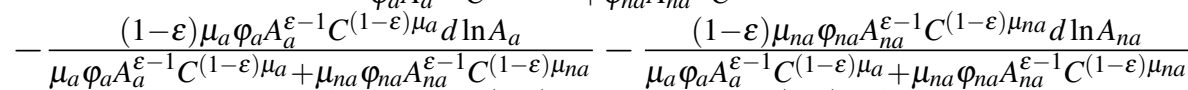

$$
\begin{aligned}
& +\quad \frac{(1-\varepsilon)\left(\mu_{a}^{2} \varphi_{a} A_{a}^{\varepsilon-1} C^{(1-\varepsilon) \mu_{a}}+\mu_{n a}^{2} \varphi_{n a} A_{m a}^{\varepsilon-1} C^{(1-\varepsilon) \mu_{n a}}\right) d \ln C}{\mu_{a} \varphi_{a} A_{a}^{\varepsilon-1} C^{(1-\varepsilon) \mu_{a}}+\mu_{n a} \varphi_{n a} A_{n a}^{\varepsilon-1} C^{(1-\varepsilon) \mu_{n a}}}
\end{aligned}
$$

$$
\begin{aligned}
& d \ln L=-\frac{\varphi_{a} A_{a}^{\varepsilon-1} C^{(1-\varepsilon) \mu_{a}} d \ln A_{a}}{\varphi_{a} A_{a}^{\varepsilon-1} C^{(1-\varepsilon) \mu_{a}}+\varphi_{n a} A_{n a}^{\varepsilon-1} C^{(1-\varepsilon) \mu_{n a}}}-\frac{\varphi_{n a} A_{n a}^{\varepsilon-1} C^{(1-\varepsilon) \mu_{n a}} d \ln A_{n a}}{\varphi_{a} A_{a}^{\varepsilon-1} C^{(1-\varepsilon) \mu_{a}}+\varphi_{n a} A_{n a}^{\varepsilon-1} C^{(1-\varepsilon) \mu_{n a}}} \\
& +\quad \frac{\left(\mu_{a} \varphi_{a} A_{a}^{\varepsilon-1} C^{(1-\varepsilon) \mu_{a}}+\mu_{n a} \varphi_{n a} A_{m a}^{\varepsilon-1} C^{(1-\varepsilon) \mu_{n a}}\right) d \ln C}{\varphi_{a} A_{a}^{\varepsilon-1} C^{(1-\varepsilon) \mu_{a}}+\varphi_{n a} A_{n a}^{\varepsilon-1} C^{(1-\varepsilon) \mu_{n a}}}
\end{aligned}
$$


From (13), we can rewrite the equations above as

$$
\begin{aligned}
d \ln C & =-\left[(\sigma+\varepsilon) l_{a}+\frac{(1-\varepsilon) \mu_{a} l_{a}}{\mu_{a} l_{a}+\mu_{n a} l_{n a}}\right] d \ln A_{a}-\left[(\sigma+\varepsilon) l_{n a}+\frac{(1-\varepsilon) \mu_{n a} l_{n a}}{\mu_{a} l_{a}+\mu_{n a} l_{n a}}\right] d \ln A_{n a} \\
& +\quad\left[(\sigma+\varepsilon)\left(\mu_{a} l_{a}+\mu_{n a} l_{n a}\right)+\frac{(1-\varepsilon)\left(\mu_{a}^{2} l_{a}+\mu_{n a}^{2} l_{n a}\right)}{\mu_{a} l_{a}+\mu_{n a} l_{n a}}\right] d \ln C
\end{aligned}
$$

$$
\begin{aligned}
d \ln L & =-l_{a} d \ln A_{a}-l_{n a} d \ln A_{n a} \\
& +\left(\mu_{a} l_{a}+\mu_{n a} l_{n a}\right) d \ln C
\end{aligned}
$$

Solving $d \ln C$ from (38) yields (18), and substituting (18) into (39) and simplifying yields (19).

\section{Invariance of the Agriculture's Share of Employment to the Scale of $\mu_{a}$ and $\mu_{n a}$}

We prove here that for any exogenously given $L_{t}$, the solution of the agriculture's share of employment from equation (12) and (13), $l_{a t}\left(\varphi_{a}, \varepsilon, \mu_{a}, \mu_{n a}\right)$ is invariant to the common scale of $\left(\mu_{a}, \mu_{n a}\right)$. First, let $C_{t}^{*}\left(\varphi_{a}, \varepsilon, \mu_{a}, \mu_{n a}\right)$ be the solution to equation (12) for the given $L_{t}$. It can be shown that the solution is unique and the corresponding agriculture's share of employment is

$$
l_{a t}=\frac{\frac{\varphi_{a}}{1-\varphi_{a}}\left(\frac{A_{a t}}{A_{\text {nat }}}\right)^{\varepsilon-1} C_{t}^{*(1-\varepsilon)\left(\mu_{a}-\mu_{n a}\right)}}{1+\frac{\varphi_{a}}{1-\varphi_{a}}\left(\frac{A_{a t}}{A_{n a t}}\right)^{\varepsilon-1} C_{t}^{*(1-\varepsilon)\left(\mu_{a}-\mu_{n a}\right)}} .
$$

Let $\mu_{a}^{\prime}=\eta \mu_{a}$ and $\mu_{n a}^{\prime}=\eta \mu_{n a}$ for an arbitrary positive constant $\eta$. Equation (12) and (13) now become

$$
L_{t}=L_{a t}+L_{n a t}=\left(\varphi_{a} A_{a t}^{\varepsilon-1} C_{t}^{(1-\varepsilon) \eta \mu_{a}}+\varphi_{n a} A_{n a t}^{\varepsilon-1} C_{t}^{(1-\varepsilon) \eta \mu_{n a}}\right)^{\frac{1}{1-\varepsilon}}
$$

and

$$
l_{a t}^{\prime}=\frac{\frac{\varphi_{a}}{1-\varphi_{a}}\left(\frac{A_{a t}}{A_{\text {nat }}}\right)^{\varepsilon-1} C_{t}^{(1-\varepsilon) \eta\left(\mu_{a}-\mu_{n a}\right)}}{1+\frac{\varphi_{a}}{1-\varphi_{a}}\left(\frac{A_{a t}}{A_{\text {nat }}}\right)^{\varepsilon-1} C_{t}^{(1-\varepsilon) \eta\left(\mu_{a}-\mu_{n a}\right)}} .
$$

Let $C_{t}^{\prime}=C_{t}^{\eta}$. Then, we can rewrite the two equation as

$$
L_{t}=L_{a t}+L_{n a t}=\left(\varphi_{a} A_{a t}^{\varepsilon-1} C_{t}^{\prime}(1-\varepsilon) \mu_{a}+\varphi_{n a} A_{n a t}^{\varepsilon-1} C_{t}^{\prime(1-\varepsilon) \mu_{n a}}\right)^{\frac{1}{1-\varepsilon}}
$$

and

$$
l_{a t}^{\prime}=\frac{\frac{\varphi_{a}}{1-\varphi_{a}}\left(\frac{A_{a t}}{A_{\text {nat }}}\right)^{\varepsilon-1} C_{t}^{\prime(1-\varepsilon)\left(\mu_{a}-\mu_{n a}\right)}}{1+\frac{\varphi_{a}}{1-\varphi_{a}}\left(\frac{A_{a t}}{A_{\text {nat }}}\right)^{\varepsilon-1} C_{t}^{\prime(1-\varepsilon)\left(\mu_{a}-\mu_{n a}\right)}} .
$$


Since equation (41) has a unique solution, we have $C_{t}^{\prime}=C_{t}^{*}$. From (40) and 42, then, we know that $l_{a t}^{\prime}=l_{a t}$.

\section{E Variance Decomposition}

Table 14: Variance Decomposition of Aggregate Output: Alternative Ordering

\begin{tabular}{|c|c|c|c|c|}
\hline \multirow[b]{3}{*}{ Forecast Horizon } & \multicolumn{2}{|c|}{ Data } & \multicolumn{2}{|c|}{ Model } \\
\hline & (1) & (2) & (3) & (4) \\
\hline & $\varepsilon_{n a}$ & $\varepsilon_{a}$ & $\varepsilon_{n a}$ & $\varepsilon_{a}$ \\
\hline \multirow[t]{2}{*}{1} & 0.62 & 0.17 & 0.64 & 0.27 \\
\hline & {$[0.41,0.83]$} & {$[-0.05,0.38]$} & {$[0.41,0.87]$} & {$[0.03,0.51]$} \\
\hline \multirow[t]{2}{*}{2} & 0.52 & 0.26 & 0.56 & 0.34 \\
\hline & {$[0.27,0.78]$} & {$[-0.02,0.53]$} & {$[0.29,0.82]$} & {$[0.06,0.62]$} \\
\hline \multirow[t]{2}{*}{3} & 0.48 & 0.29 & 0.53 & 0.36 \\
\hline & {$[0.20,0.76]$} & {$[-0.02,0.61]$} & {$[0.25,0.81]$} & {$[0.06,0.66]$} \\
\hline \multirow[t]{2}{*}{4} & 0.46 & 0.31 & 0.52 & 0.36 \\
\hline & {$[0.16,0.75]$} & {$[-0.03,0.64]$} & {$[0.24,0.80]$} & {$[0.05,0.67]$} \\
\hline
\end{tabular}

Note: Column (1) and (2) show the percentage of variance of the $k$-step-ahead forecast error in $\triangle \ln Y_{t}$ due to the non-agricultural labour productivity shock $\varepsilon_{n a}$, and the agricultural labour productivity shock $\varepsilon_{a}$, respectively. In column (3) and (4), we perform the same variance decomposition exercise using the simulated output data. 95\% confidence interval shown in square brackets.

\section{F Model with Trade and Investment}

In this section, we set up the model with exogenous investment and net export. The social planner now solves the following problem:

$$
\max _{c_{a t}, c_{n a t}, L_{a t}, L_{n a t}, C_{t}}\left\{N_{t}\left[C_{t}-\frac{B_{t}}{1+\sigma} L_{t}^{1+\sigma}\right]\right\}
$$

subject to (3) and the following constraints:

$$
\begin{gathered}
c_{a t}+n x_{a t}=A_{a t} L_{a t}, \\
c_{n a t}+x_{t}+n x_{n a t}=A_{n a t} L_{n a t}, \\
L_{a t}+L_{n a t}=L_{t} .
\end{gathered}
$$

where $x_{t}$ is investment, and $n x_{i t}$ is the sector $i$ 's net export for $i=a, n a$. We assume $x_{t}, n x_{a t}$, and $n x_{n a t}$ are exogenously taken by the social planner. Therefore, the FOCs of the social planner's 
problem are the same as in the benchmark case and imply the following:

$$
\begin{gathered}
\frac{A_{a t}}{A_{n a t}}=\left(\frac{\varphi_{n a}}{\varphi_{a}}\right)^{\frac{1}{\varepsilon}} C_{t}^{\frac{(1-\varepsilon)\left(\mu_{n a}-\mu_{a}\right)}{\varepsilon}}\left(\frac{c_{n a t}}{c_{a t}}\right)^{-\frac{1}{\varepsilon}} \\
\frac{B_{t} L_{t}^{\sigma}}{A_{a t}}=\frac{\varphi_{a}^{\frac{1}{\varepsilon}} C_{t}^{\frac{(1-\varepsilon) \mu_{a}}{\varepsilon}}-\lambda c_{a t}^{-\frac{1}{\varepsilon}}}{\left(\mu_{a} \varphi_{a}^{\frac{1}{\varepsilon}} C_{t}^{\frac{(1-\varepsilon) \mu_{a}}{\varepsilon}}-1 c_{a t}^{\frac{\varepsilon-1}{\varepsilon}}+\mu_{n a} \varphi_{n a}^{\frac{1}{\varepsilon}} C_{t}^{\frac{(1-\varepsilon) \mu_{n a}}{\varepsilon}}-1 c_{n a t}^{\frac{\varepsilon-1}{\varepsilon}}\right)} .
\end{gathered}
$$

We also assume that in equilibrium :

$$
\begin{aligned}
& x_{t}=\tau_{x t} A_{\text {nat }} L_{\text {nat }}, \\
& n x_{i t}=\tau_{n x_{i}} A_{i t} L_{i t},
\end{aligned}
$$

where $\tau_{x t}$ and $\tau_{n x_{i} t}$ are exogenous investment and net export wedges. These ratios are calculated directly from the Penn World Table 9.1 and the GGDC 10-Sector Database. ${ }^{11}$

Using equation (46) and (47), together with (43), (44), (45), and (3), we can solve for $c_{a t}, c_{n a t}$, $C_{t}, L_{a t}, L_{n a t}$, and $L_{t}$.

\section{G Alternative Shock Process}

In this section, we describe in details the estimation of the stochastic shock process for labour productivities in Section 7. To be specific, we assume that the sector labour productivities follow the following vector autoregressive process

$$
\left[\begin{array}{c}
A_{n a t} \\
A_{a t}
\end{array}\right]=\rho\left[\begin{array}{c}
A_{n a t-1} \\
A_{a t-1}
\end{array}\right]+\varepsilon_{t}
$$

where $\varepsilon_{t} \sim N(0, \Sigma)$ and $A_{i t}$ is the cyclical labour productivity, $i \in\{a, n a\}$. We assume that there is no cross persistence between $A_{a t}$ and $A_{\text {nat }}$. The estimated shock process for China is

$$
\rho=\left[\begin{array}{cc}
0.52 & 0 \\
0 & 0.72
\end{array}\right]
$$

and

$$
\Sigma=\left[\begin{array}{cc}
0.016^{2} & 0.055 \times 0.016 \times 0.026 \\
0.055 \times 0.016 \times 0.026 & 0.026^{2}
\end{array}\right]
$$

\footnotetext{
${ }^{11}$ The Penn World Table reports the share of net exports and investment in aggregate GDP. We convert them to shares in sector GDP by dividing the corresponding sector shares of aggregate GDP (in real terms valued at 2005 international prices) that we calculate from the GGDC 10-Sector Database. Since the shares in the Penn World Table 9.1 are valued at 2011 international prices, while the real sector GDP shares are valued at 2005 international prices, we implicitly assume here that the relative prices from the 2005 PPPs are approximately the same as the relative prices from the 2011 PPPs.
} 
The estimated shock process for the US is

$$
\rho=\left[\begin{array}{cc}
0.56 & 0 \\
0 & 0.09
\end{array}\right]
$$

and

$$
\Sigma=\left[\begin{array}{cc}
0.010^{2} & 0.15 \times 0.010 \times 0.079 \\
0.15 \times 0.010 \times 0.079 & 0.079^{2}
\end{array}\right] .
$$

We then simulate the shock process for 40 periods and add it back to the productivity trend. The model is then solved using the constructed productivity. We repeat the simulation for 3000 times and compute the average business cycle moments. Column (5) and (10) of Table 12 report the simulation results under this specification.

\section{H Calibration and Simulation with Revised Data}

Brandt and Zhu (2010) argue that the National Bureau of Statistics employment series overestimate employment in agriculture. They find that the official agricultural employment series can be closely approximated by the Total Rural Employment minus the Employment of the Township and Village Enterprises (TVEs). This series overestimates agricultural employment because nonagricultural workers in rural private enterprises and rural individual enterprises (those that employ less than eight employees) are counted as agricultural workers. To better account for employment in agriculture, we follow Brandt and Zhu (2010) and construct the agricultural employment series as the total rural employment minus rural employments in TVEs, private enterprises, and individual enterprises. Unfortunately, the information needed for revising the employment series after 2010 is not readily available, hence our revised data series cover 33 years from 1978 to 2010. There has also been concerns about the official GDP deflators. See, e.g., Young (2003), Brandt and Zhu (2010), and Nakamura, Steinsson, and Liu (2016). In this section, we also follow Brandt and Zhu (2010) and construct alternative price deflators for both the agricultural and non-agricultural sectors. 
Figure 8: Revised Employment Data in China
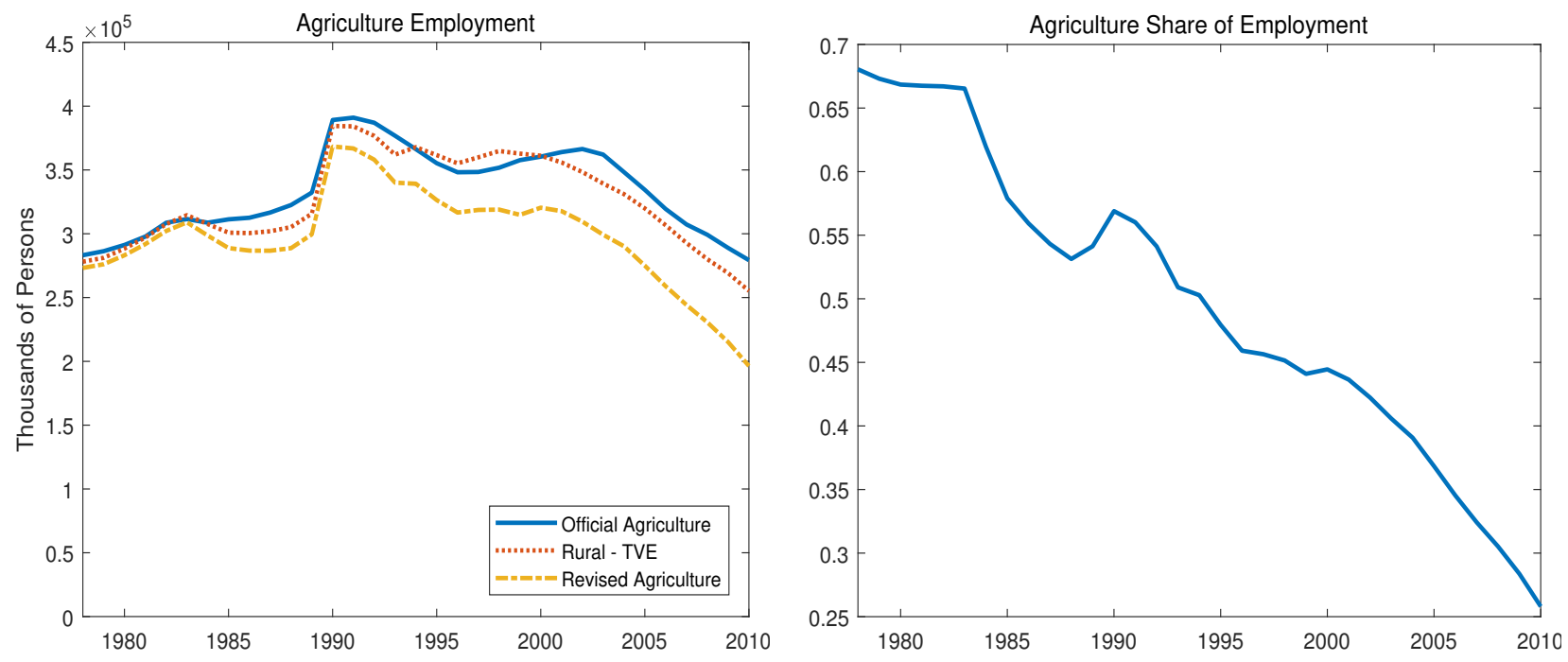

The official and the revised agricultural employment series are plotted in the left panel of Figure 8. Note that this revised agricultural employment series still has the same problem as the official total employment series for the years prior to 1990. To generate a consistent agricultural employment series for the entire period, for each year we first use the revised agricultural employment and the official total employment to calculate the share of employment in agriculture; we then calculate the final revised agricultural employment as the product of the share and the revised total employment; and finally we calculate the revised non-agricultural employment as the difference between the revised total employment and the revised agricultural employment. The right panel of Figure 8 plots the agriculture's share of total employment using the revised data series.

Given the revised data for GDP and employment series, we estimate our non-homothetic CES model and simulate the model implies structural change and business cycle moments. The estimation results are reported in Table 15 and simulation results in Figure 9 and Table 16. They show that our model matches the long-run structural change and short-run business cycle fluctuations in China well. 
Figure 9: Structural Change: Revised Data
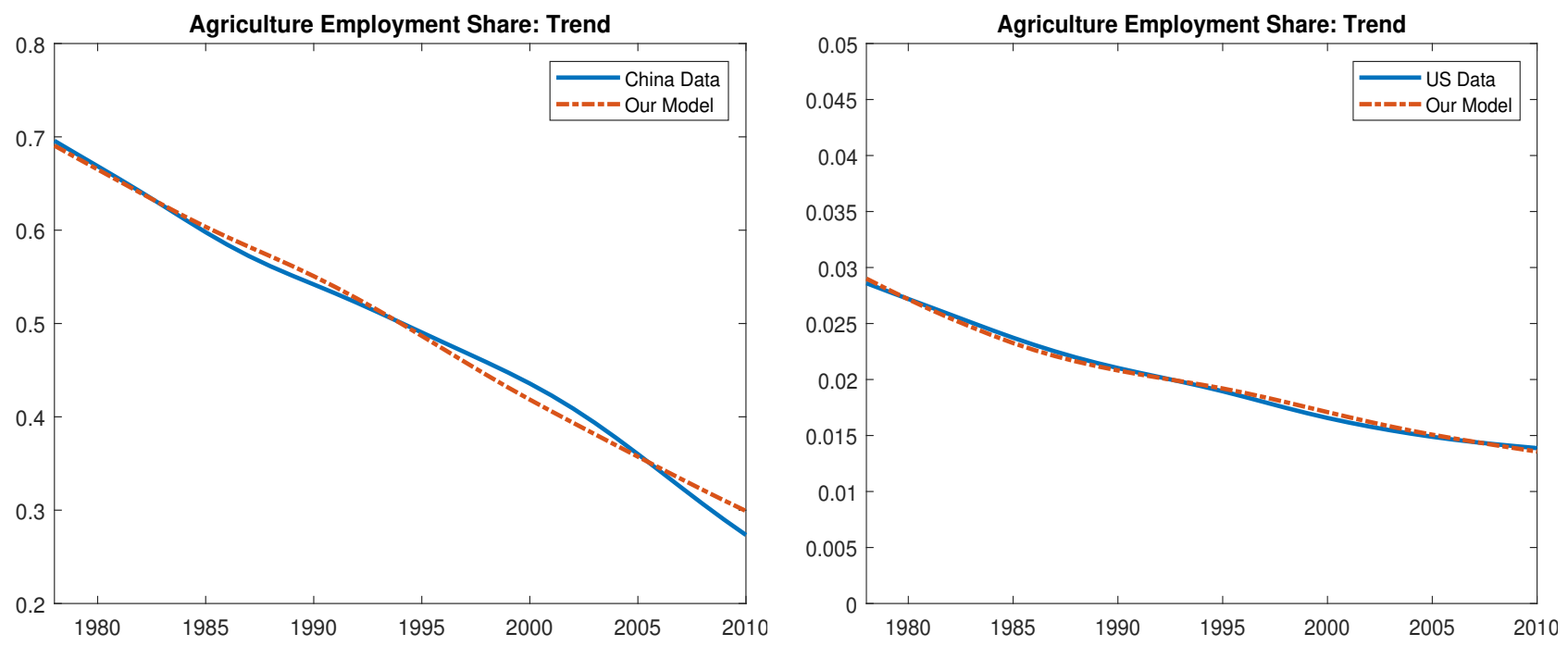

Table 15: Calibration with Revised Data

\begin{tabular}{|c|c|c|c|c|}
\hline Parameter & Description & Target & China Value & US Value \\
\hline \multirow[t]{2}{*}{$\varphi_{a}$} & preference weight & average of agriculture & 0.360 & 0.0772 \\
\hline & of agriculture & employment share & {$[0.268,0.452]$} & {$[0.0768,0.0777]$} \\
\hline \multirow[t]{2}{*}{$\varepsilon$} & elasticity of substitution & trend of agriculture & 0.475 & 0.475 \\
\hline & between two goods & employment share in China & {$[0.194,0.756]$} & {$[0.194,0.756]$} \\
\hline$\mu_{a}$ & $\begin{array}{l}\text { income elasticity } \\
\text { of agricultural good }\end{array}$ & normalization & 1 & 1 \\
\hline \multirow[t]{2}{*}{$\mu_{n a}$} & income elasticity & trend of agriculture & 5.069 & 5.069 \\
\hline & of non-agricultural good & employment share in China & {$[-2.242,12.380]$} & {$[-2.242,12.380]$} \\
\hline$\sigma$ & $\begin{array}{l}\text { inverse of Frisch elasticity } \\
\text { of labour supply }\end{array}$ & literature & 0.6 & 0.6 \\
\hline
\end{tabular}

Note: $95 \%$ confidence interval shown in square brackets. 
Table 16: Benchmark Simulation: Revised Data

\begin{tabular}{|c|c|c|c|c|}
\hline & China & & US & \\
\hline & Data & Model & Data & Model \\
\hline (A) & & & & \\
\hline$\sigma(L) / \sigma(Y)$ & 0.11 & 0.13 & 0.70 & 0.23 \\
\hline$\rho(L, Y)$ & 0.09 & -0.03 & 0.87 & 0.87 \\
\hline (B) & & & & \\
\hline$\sigma\left(L_{a}\right) / \sigma\left(Y_{a}\right)$ & 0.70 & 0.82 & 0.33 & 1.08 \\
\hline$\sigma\left(L_{n a}\right) / \sigma\left(Y_{n a}\right)$ & 0.75 & 0.54 & 0.71 & 0.24 \\
\hline$\rho\left(L_{a}, Y_{a}\right)$ & 0.24 & -0.92 & -0.05 & -0.99 \\
\hline$\rho\left(L_{n a}, Y_{n a}\right)$ & 0.88 & 0.83 & 0.87 & 0.86 \\
\hline (C) & & & & \\
\hline$\rho\left(L_{a}, L\right)$ & 0.15 & 0.75 & -0.20 & 0.00 \\
\hline$\rho\left(L_{n a}, L\right)$ & 0.31 & -0.34 & 1.00 & 0.96 \\
\hline$\rho\left(L_{a}, Y\right)$ & -0.77 & -0.60 & -0.34 & -0.15 \\
\hline$\rho\left(L_{n a}, Y\right)$ & 0.83 & 0.86 & 0.87 & 0.87 \\
\hline (D) & & & & \\
\hline$\rho\left(L_{a}, L_{n a}\right)$ & -0.83 & -0.83 & -0.23 & -0.28 \\
\hline$\rho\left(L_{a} / L_{n a}, A_{a} / A_{n a}\right)$ & -0.29 & -0.86 & -0.27 & -0.99 \\
\hline$\rho\left(L_{a} / L_{n a}, Y\right)$ & -0.84 & -0.76 & -0.69 & -0.22 \\
\hline
\end{tabular}

Note: $\sigma(x)$ is the standard deviation of variable $x . \rho(x, y)$ is the correlation of variable $x$ and $y . L$ and $Y$ are aggregate employment rate and output per capita. $L_{i}, Y_{i}$ and $A_{i}$ are sector employment, output and labour productivity, where $i \in\{a, n a\}$. Variables are detrended using hp-filter with smoothing parameter of 100 . 


\section{References}

[1] Acemoglu, Daron, and Veronica Guerrieri. 2008. "Capital Deepening and Non-Balanced Economic Growth.” Journal of Political Economy, 116, 467-498.

[2] Boppart, Timo. 2014. "Structural Change and The Kaldor Facts in a Growth Model with Relative Price Effects and Non-Gorman Preferences.” Econometrica 82 (6), 2167-2196.

[3] Brandt, Loren, Chang-Tai Hsieh and Xiaodong Zhu 2008. "Growth and Structural Transformation in China" in Loren Brandt and Thomas Rawski ed. China's Great Economic Transformation, pp. 569-632, Cambridge University Press.

[4] Brandt, Loren, and Xiaodong Zhu. 2000. "Redistribution in a Decentralized Economy: Growth and Inflation in China under Reform.” Journal of Political Economy 108 (2), 422439.

[5] Brandt, Loren, and Xiaodong Zhu. 2010. “Accounting for China’s Growth.” University of Toronto Working Paper No. 394.

[6] Caselli, Francesco and Coleman, Wilbur John, II. 2001. "The US Structural Transformation and Regional Convergence: A Reinterpretation.” Journal of Political Economy 109, 584-616.

[7] Chang, Chun, Kaiji Chen, Daniel F. Waggoner, and Tao Zha. 2016. "Trends and Cycles in China's Macroeconomy." NBER Macroeconomics Annual 30, 1-84.

[8] Chari, V. V., Patrick J. Kehoe, and Ellen R. McGrattan. 2007. "Business Cycle Accounting." Econometrica 75, 781-837.

[9] Cooley, Thomas F., and Prescott, Edward C. 1995. "Economic Growth and Business Cycles." in the Frontiers of Business Cycle Research, edited by Thomas F. Cooley, Princeton University Press.

[10] Comin, Diego, Danial Lashkari, and Marti Mestieri. 2020. "Structural Change with Long-run Income and Price Effects." Econometrica, forthcoming.

[11] Da-Rocha, José M., and Diego Restuccia. 2006. "The Role of Agriculture in Aggregate Business Cycles." Review of Economic Dynamics 9, 455-482.

[12] Greenwood, Jeremy, Zvi Hercowitz, and Gregory Huffman. 1988. "Investment, Capacity Utilization, and the Real Business Cycle." American Economic Review 78 (3).

[13] Hanoch, Giora. 1975. "Production and Demand Models with Direct or Indirect Implicit Additivity.” Econometrica, Vol. 43, No. 3 (May, 1975), pp. 395-419

[14] He, Qing, Terence Tai-Leung Chong, and Kang Shi. 2009. "What accounts for Chinese Business Cycle?" China Economic Review 20, 650-661.

[15] Herrendorf, Berthold, Richard Rogerson, and Akos Valentinyi. 2013. "Two Perspectives on Preferences and Structural Transformation.” American Economic Review, Vol. 103, No. 7 , pp. 2752-89. 
[16] Kongsamut, Piyabha, Sergio Rebelo and Danyang Xie. 2001. "Beyond Balanced Growth." Review of Economic Studies, 68(4), pp. 869-82.

[17] Lin, Justin Yifu. 1992. "Rural Reforms and Agriculture Growth in China." American Economic Review, Vol. 82, No.1, pp. 34-51.

[18] Moro, Alessio. 2012. "The Structural Transformation between Manufacturing and Services and the Decline in the US GDP Volatility." Review of Economic Dynamics, Vol 12 (3), pp.402415.

[19] Nakamura, Emi, Jon Steinsson, and Miao Liu. 2016. "Are Chinese Growth and Inflation Too Smooth? Evidence from Engle Curves." American Economic Journal: Macroeconomics, 8 (3): 113-144.

[20] Ngai, L. Rachel and Christopher A. Pissarides. 2007. "Structural Change in a Multisector Model of Growth.” American Economic Review, 97, 429-443.

[21] Storesletten, Kjetil, Bo Zhao, and Fabrizio Zilibotti. 2019. "Business Cycle During Structural Change: Arthur Lewis's Theory from a Neoclassical Perspective.” NBER Working Paper No. 26181

[22] Timmer, Marcel P., Gaaitzen de Vries, and Klaas de Vries. 2015. "Patterns of Structural Change in Developing Countries." in the Routledge Handbook of Industry and Development. pp. 65-83. Routledge.

[23] Young, Alwyn. 2003. "Gold into Base Metals: Productivity Growth in the People's Republic of China during the Reform Period." Journal of Political Economy, 111 (6): 1220-1261. 